Research Article

\title{
Dowel Behavior of Rebars in Small Concrete Block for Sliding Slab Track on Railway Bridges
}

\author{
Seong-Cheol Lee, ${ }^{1}$ Sangmin Park, ${ }^{2}$ Jaeha Lee, ${ }^{2}$ and Kyoung-Chan Lee $\mathbb{i D}^{3}$ \\ ${ }^{1}$ Department of Civil Engineering, Kyungpook National University, 80 Daehakro, Bukgu, Daegu 41566, Republic of Korea \\ ${ }^{2}$ Department of Civil Engineering, Korea Maritime and Ocean University, 727 Taejong-ro, Yeongdo-Gu, Busan 49112, \\ Republic of Korea \\ ${ }^{3}$ Advanced Railroad Civil Engineering Divison, Korea Railroad Research Institute (KRRI), 176 Cheoldobangmulgwan-ro, \\ Uiwang-si, Gyeonggi-do 16105, Republic of Korea
}

Correspondence should be addressed to Kyoung-Chan Lee; eclip77@gmail.com

Received 4 January 2018; Accepted 8 February 2018; Published 11 April 2018

Academic Editor: João M. P. Q. Delgado

Copyright (C) 2018 Seong-Cheol Lee et al. This is an open access article distributed under the Creative Commons Attribution License, which permits unrestricted use, distribution, and reproduction in any medium, provided the original work is properly cited.

\begin{abstract}
In recent years, several studies have investigated the sliding slab track for railway bridges. In the design of sliding slab tracks, one of the most important considerations is to evaluate the shear capacity of the lateral supporting concrete blocks in which dowel rebars are embedded. The predictions of the dowel behavior of rebars by existing models are considerably different. Therefore, in this study, the actual dowel behavior of the rebars embedded in a small concrete block was extensively investigated through experiments. Test variables were concrete compressive strength, dowel rebar diameter and yield strength, specimen thickness, and dowel rebar spacing. Existing model predictions were considerably different from test results. The maximum dowel force increased as concrete compressive strength and dowel rebar diameter increased, while it did not increase considerably with other test variables. Unlike in existing models, the shear slip at the maximum dowel force decreased as the dowel rebar diameter increased. Existing models significantly underestimated the maximum dowel force of the dowel rebars with small diameters and overestimated it for the dowel rebars with large diameters. This work can be useful for developing a more rational model to represent the actual dowel behavior of the rebars embedded in small concrete blocks.
\end{abstract}

\section{Introduction}

Modern railway bridges are equipped with continuously welded rails (CWRs) without any seams to improve riding comfort and the high-speed driving of a train. In such railway bridges, additional axial stresses can be caused on rails owing to the expansion and contraction of the bridge structure because of temperature change. This behavior is referred to as the track-bridge interaction. Simply supported railway bridges with short spans have been commonly adopted to suppress this effect. The interaction effect should be carefully controlled through special types of fasteners or rail expansion joints in the case of long span bridges. However, the effectiveness of these methods is limited, and they may cause additional problems such as maintenance issues.

Recently, Lee et al. [1] conducted preliminary research on the design of a sliding slab track, in which a low friction sliding layer is placed between the bottom of a slab track and the top of a bridge deck as an alternative method of reducing track-bridge interaction. The sliding slab track system separates the longitudinal behavior of the concrete slab track and bridge deck to prevent the longitudinal displacement due to the temperature expansion and contraction of the bridge from being transmitted to the CWR through the slab track. Lee et al. [2,3] reported that the additional axial stress along the rail due to the track-bridge interaction effect was reduced by $80-90 \%$ when the sliding 


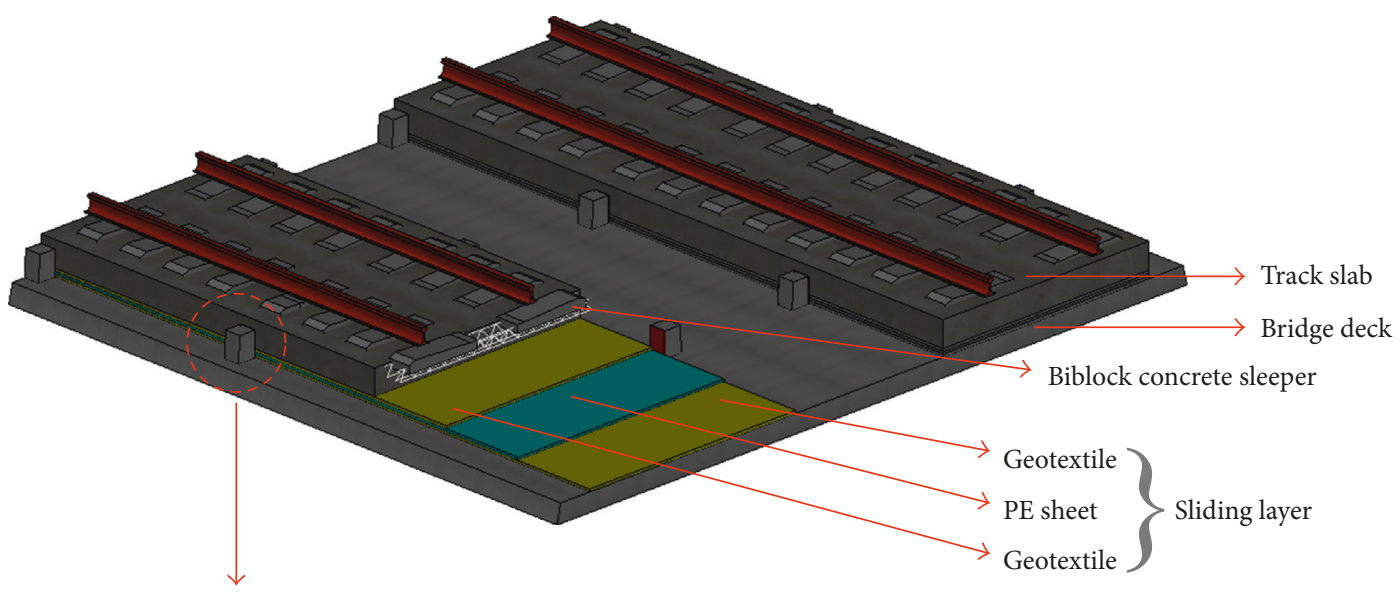

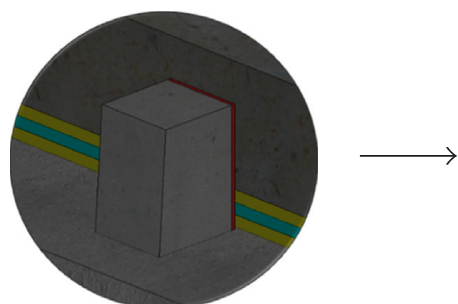

Lateral supporting block

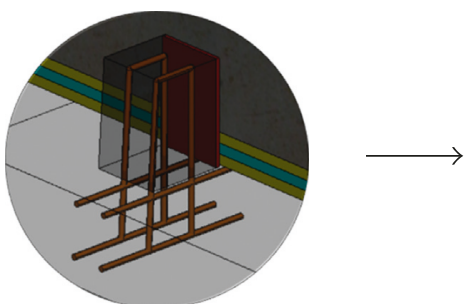

Dowel rebars in the block

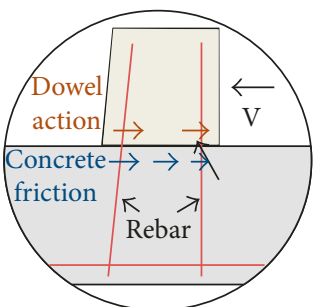

Resistance mechanism

Figure 1: Perspective view of sliding slab track including lateral supporting blocks.

TABLE 1: Summary of design specifications and previous models for dowel behavior of rebar.

\begin{tabular}{|c|c|}
\hline Model & Equations \\
\hline Soroushian et al. [5] & $\begin{array}{c}D(s)=D_{\max }\left(s / \mathrm{s}_{\max }\right)^{0.5} \\
D_{\max }=0.5 f_{\mathrm{b}}\left(0.37 \gamma d_{\mathrm{b}}-c\right)^{2}+ \\
0.45 f_{\mathrm{y}} d_{\mathrm{b}}^{2}\left(1-T^{2} / T_{\mathrm{y}}^{2}\right) / \gamma \\
s_{\max }=2.43 \times 10^{-5} D_{\max }+0.24 \mathrm{~mm} \\
\text { where } f_{\mathrm{b}}=37.6 \sqrt{f_{\mathrm{c}}^{\prime}} / \sqrt[3]{d_{\mathrm{b}}}, \gamma=\sqrt[4]{E_{\mathrm{s}} / K_{\mathrm{f}} d_{\mathrm{b}}} \\
K_{\mathrm{f}}=271.7 \mathrm{MPa} / \mathrm{mm}, \text { and } c=0.05 f_{\mathrm{y}} d_{\mathrm{b}} / f_{\mathrm{c}}^{\prime}\end{array}$ \\
\hline Randl [11] & $\begin{array}{l}\text { (i) Detailed model } \\
\qquad D_{\max }=p_{\max } d_{\mathrm{b}}^{2}\left[\left(0.46 L / d_{\mathrm{b}}\right)+\left(0.187 f_{\mathrm{y}} d_{\mathrm{b}} / p_{\max } L\right)\right. \\
\left.\quad-0.005\left(d_{\mathrm{b}} / \mathrm{L}\right)^{3}\left(f_{\mathrm{y}} / \mathrm{p}_{\max }\right)^{2}\right] \\
\text { where } p_{\max }=3 \sim 4 \text { times of } f_{\mathrm{cwm}} L=\sqrt[4]{\left(4 E_{\mathrm{s}} I / 500 d_{\mathrm{b}}\right)} \\
\text { (ii) Simple model } \\
\qquad D_{\max }=1.5 A_{\mathrm{s}} \sqrt{f_{\mathrm{y}}} \sqrt{f_{\mathrm{cwm}}}, \\
\text { where } f_{\mathrm{cwm}} \text { is compressive strength of concrete cube }\end{array}$ \\
\hline MC10 [12] & $\begin{array}{c}D(s)=D_{\max }\left(s / s_{\max }\right)^{0.5} \\
D_{\max }=\kappa_{2, \max } A_{\mathrm{s}} \sqrt{f_{\text {co }} f_{\mathrm{y}}} \leq\left(A_{\mathrm{s}} f_{\mathrm{y}} / \sqrt{3}\right), \text { where } \\
\kappa_{2, \text { max }} \leq 1.6 \text { for } \mathrm{C} 20 \sim \mathrm{C} 50 \text { concrete } s_{\max } \text { is } 1 \sim 2 \text { times } \\
\text { the dowel rebar diameter }\end{array}$ \\
\hline
\end{tabular}

track system was adopted, as compared to the conventional slab track system.

As bridges and concrete slab tracks are separated from each other by sliding layers, it is necessary to implement supporting structures for resisting lateral load, which is caused by a train nosing force, lateral wind, centrifugal loads along curved railways, and temperature change in curved rails. Figure 1 is a conceptual drawing of a sliding slab track including a bridge deck, a sliding layer, and lateral supporting concrete blocks. As shown in the figure, several rebars are installed in the lateral supporting concrete blocks so that they can resist lateral load through the dowel behavior of the rebars.

For the design of lateral supporting concrete blocks, Lee et al. [4] employed an existing model $[5,6]$ to consider the lateral load that can be resisted by the dowel behavior of rebars. Even though the structural behavior of dowel rebars is the primary issue in the design, experimental verification is relatively limited for the dowel behavior of rebars in a small concrete member such as a lateral supporting 


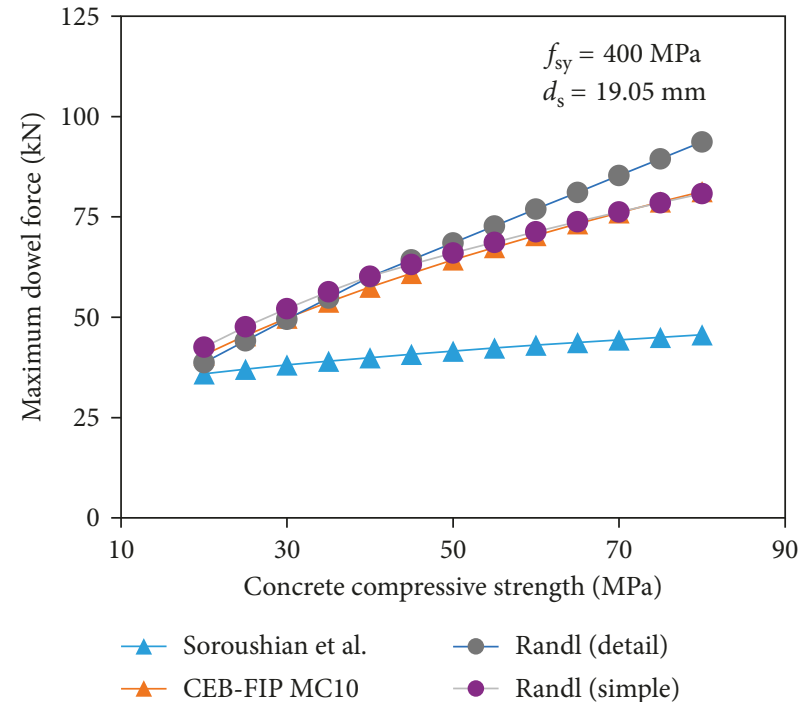

(a)

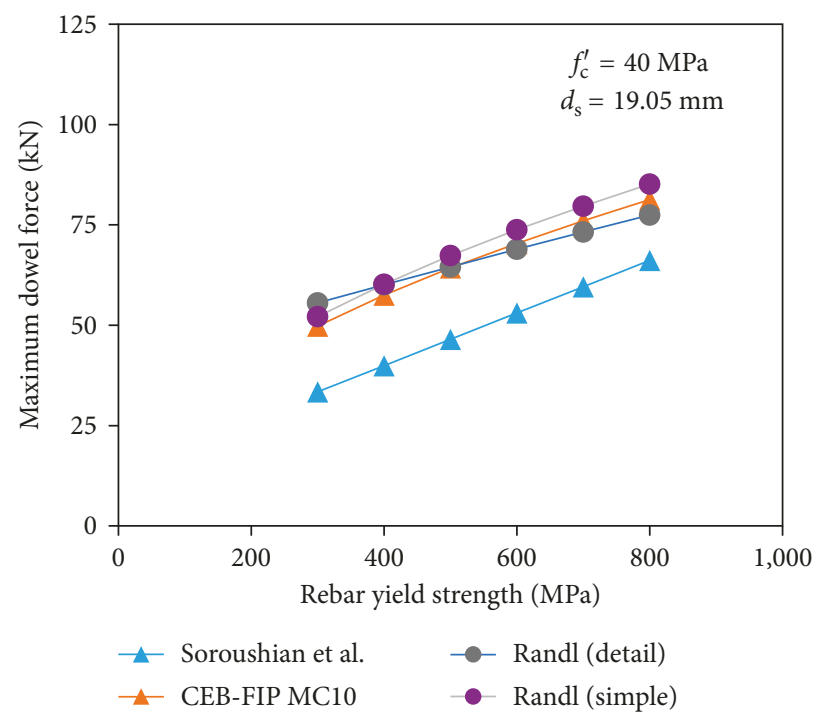

(b)

FIGURE 2: Comparison of existing models for the maximum dowel force: (a) effect of concrete compressive strength; (b) effect of rebar yield strength.

TABle 2: Summary of test specimens for dowel behavior of rebar.

\begin{tabular}{|c|c|c|c|c|c|}
\hline Specimen & $\begin{array}{c}\text { Concrete compressive } \\
\text { strength }(\mathrm{MPa})\end{array}$ & $\begin{array}{l}\text { Dowel rebar yield } \\
\text { strength }(\mathrm{MPa})\end{array}$ & $\begin{array}{c}\text { Dowel rebar } \\
\text { diameter }(\mathrm{mm})\end{array}$ & $\begin{array}{c}\text { Dowel rebar } \\
\text { spacing }(\mathrm{mm})\end{array}$ & $\begin{array}{c}\text { Specimen } \\
\text { thickness }(\mathrm{mm})\end{array}$ \\
\hline NC-N13-200 & 30 & 400 & 12.7 & 200 & 150 \\
\hline NC-N19-150 & 30 & 400 & 19.05 & 150 & 150 \\
\hline NC-N19-200 & 30 & 400 & 19.05 & 200 & 150 \\
\hline NC-N19-250 & 30 & 400 & 19.05 & 250 & 150 \\
\hline NC-N25-200 & 30 & 400 & 25.4 & 200 & 150 \\
\hline NC-H13-200 & 30 & 600 & 12.7 & 200 & 150 \\
\hline NC-H19-200 & 30 & 600 & 19.05 & 200 & 150 \\
\hline NC-H25-200 & 30 & 600 & 25.4 & 200 & 150 \\
\hline HC-N13-200 & 60 & 400 & 12.7 & 200 & 150 \\
\hline HC-N19-200 & 60 & 400 & 19.05 & 200 & 150 \\
\hline HC-N25-200 & 60 & 400 & 25.4 & 200 & 150 \\
\hline HC-H13-200 & 60 & 600 & 12.7 & 200 & 150 \\
\hline HC-H19-150 & 60 & 600 & 19.05 & 150 & 150 \\
\hline HC-H19-200 & 60 & 600 & 19.05 & 200 & 150 \\
\hline HC-H19-250 & 60 & 600 & 19.05 & 250 & 150 \\
\hline HC-H25-200 & 60 & 600 & 25.4 & 200 & 150 \\
\hline NC-N19-200-2 & 30 & 400 & 19.05 & 200 & 200 \\
\hline NC-N19-200-2.5 & 30 & 400 & 19.05 & 200 & 250 \\
\hline
\end{tabular}

concrete block. Several studies experimentally investigated the dowel behavior of rebars; however, only one side of the rebars was embedded in concrete $[7,8]$ or dowel behavior was not perfectly extracted because of shear friction along the concrete interface $[9,10]$. In addition, several models have been presented in the literature $[5,11,12]$; however, the predictions of the dowel behavior of rebars by these models are considerably different.

Therefore, in this study, the actual dowel behavior of the rebars in a small concrete member is investigated through an extensive experimental program, focusing on the dowel behavior against concrete core [5], which is dominated by

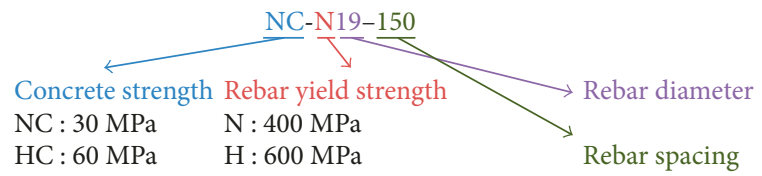

FIgURE 3: Test variables for dowel behavior of rebar in concrete.

concrete bearing strength, and not against concrete cover, which includes splitting cracks [6]. The effects of test variables on dowel behavior are examined based on experimental results. In addition, the applicability of existing 


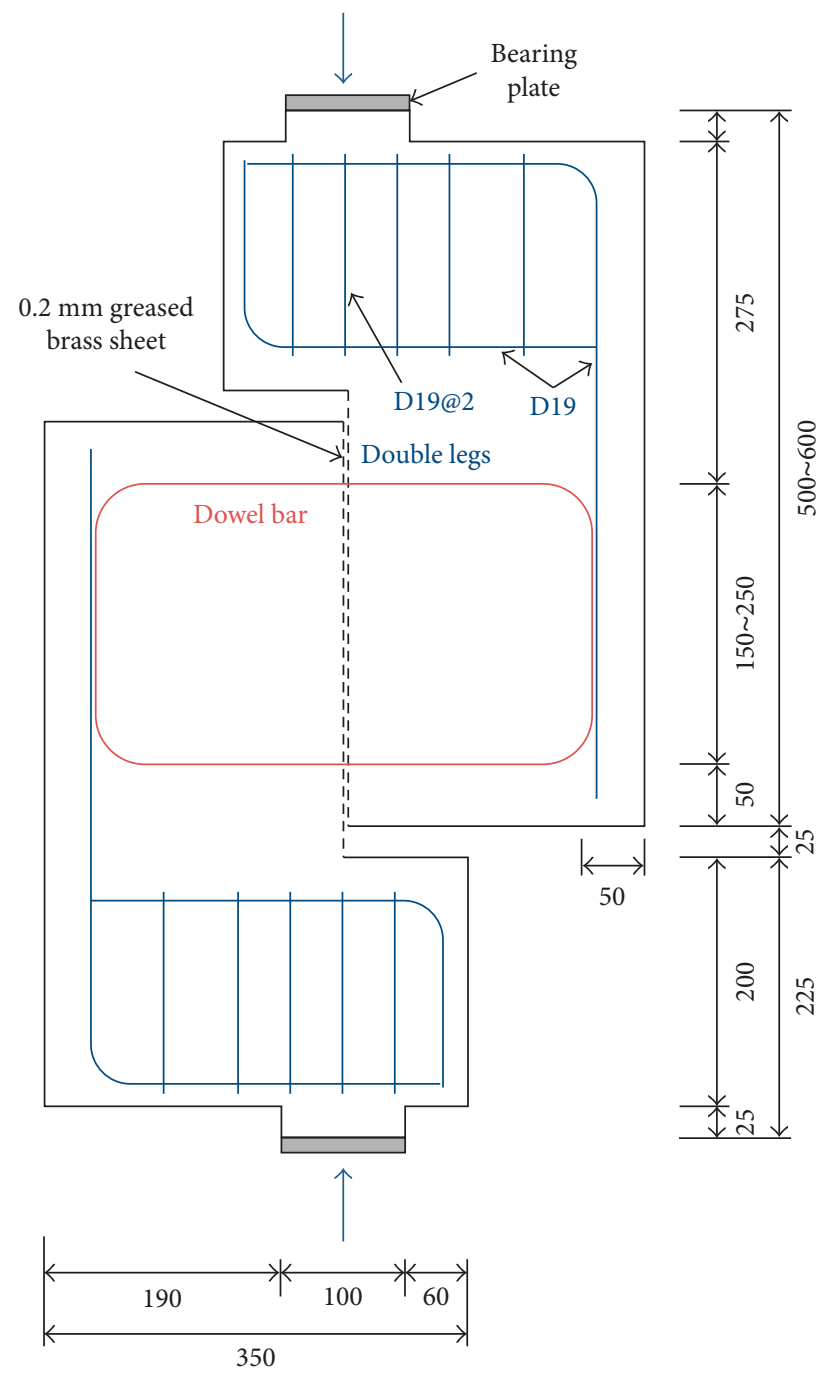

FIgURE 4: Details of test specimens.

models is investigated by comparing the experimental results with model predictions.

\section{Existing Models for Dowel Behavior of Rebars}

The existing models $[5,11,12]$ used to theoretically investigate the dowel behavior of the rebars embedded in concrete are summarized in Table 1. It is noted that only models that describe the dowel behavior of rebars against concrete core have been considered. As given in the table, MC10 [12] and Soroushian et al. [5] described the dowel force-shear slip response while Randl [11] analyzed only the maximum dowel force. The primary parameters considered in the models were concrete compressive strength, dowel rebar yield strength, and dowel rebar diameter. The model presented in MC10 is extremely similar to Randl's simple model, while the model proposed by Soroushian et al. is different because it is based on the bearing strength of the concrete under dowel rebars [13]. Randl's detailed model also considers the bearing strength of concrete; however, it is

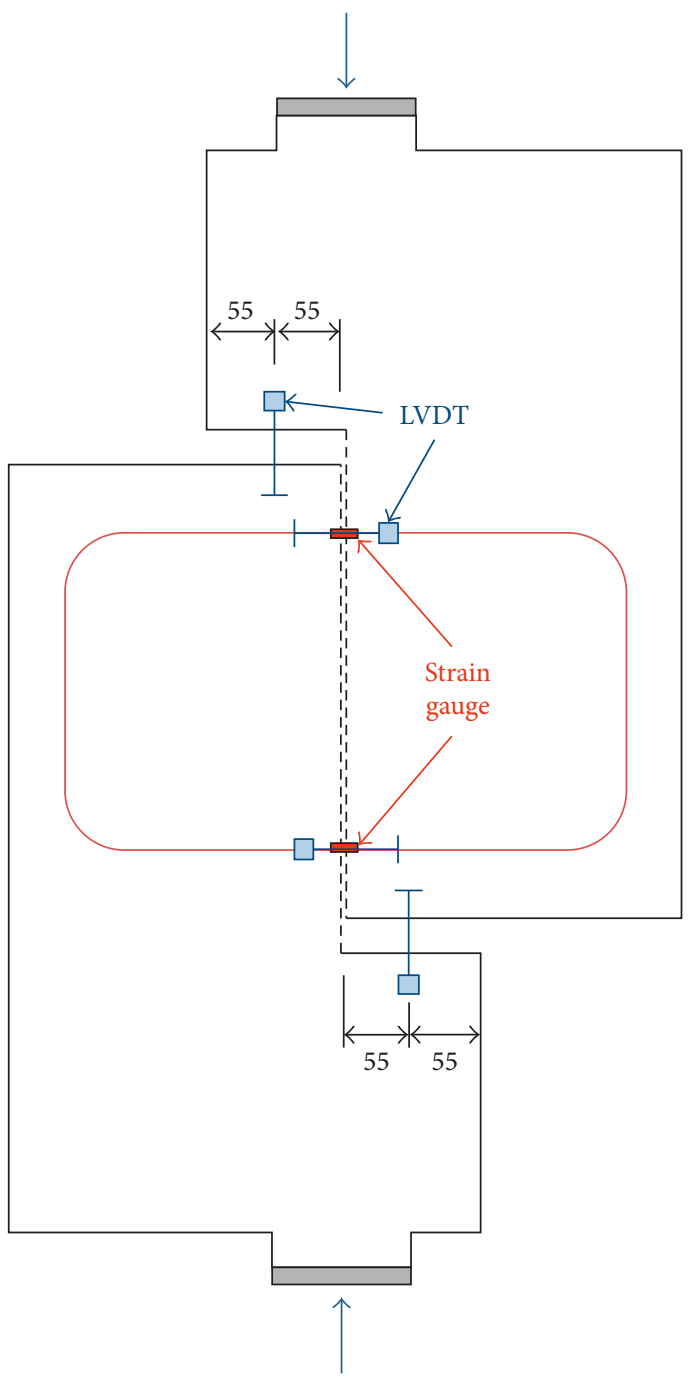

FIGURE 5: Instrumentations to measure dowel behavior of rebar.

Table 3: Properties of dowel rebar.

\begin{tabular}{lcccc}
\hline Notation & $\begin{array}{c}\text { Nominal } \\
\text { diameter } \\
(\mathrm{mm})\end{array}$ & $\begin{array}{c}\text { Nominal } \\
\text { yield } \\
\text { strength } \\
(\mathrm{MPa})\end{array}$ & $\begin{array}{c}\text { Measured } \\
\text { Yield } \\
\text { strength } \\
(\mathrm{MPa})\end{array}$ & $\begin{array}{c}\text { Tensile } \\
\text { strength } \\
(\mathrm{MPa})\end{array}$ \\
\hline N13 & 12.7 & 400.0 & 510.9 & 624.8 \\
N19 & 19.1 & 400.0 & 549.5 & 617.0 \\
N25 & 25.4 & 400.0 & 539.0 & 689.6 \\
H13 & 12.7 & 600.0 & 715.8 & 740.3 \\
H19 & 19.1 & 600.0 & 686.9 & 778.2 \\
H25 & 25.4 & 600.0 & 668.6 & 822.6 \\
\hline
\end{tabular}

fundamentally based on the deformed shape of the dowel rebar embedded in concrete.

Figure 2 shows the maximum dowel force evaluated using existing models to investigate the effect of two primary parameters (concrete and rebar strengths) on the dowel behavior of rebars. It is noted that a value of 1.6 was used for $\kappa_{2, \max }$ to consider the upper limit reported by 


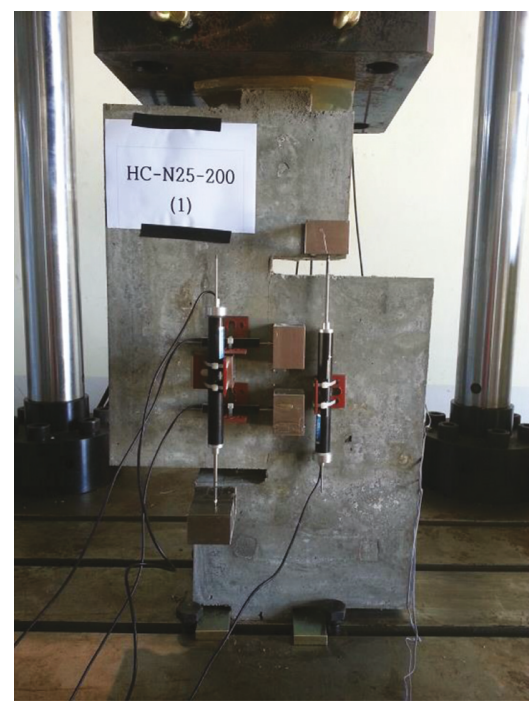

FIgURE 6: Test setup.

MC10 [12]. As seen in the figures, the models proposed by MC10 [12] and Randl [11] provide similar predictions of the maximum dowel force and its variation with concrete compressive strength or dowel rebar yield strength. On the contrary, the maximum dowel force predicted by Soroushian et al.'s model is lower than that predicted by other models. This trend is more evident when concrete compressive strength is increased. As verifications conducted in literature have typically focused on normal strength materials $[5,11]$, additional experiments should be conducted to investigate the dowel behavior of the rebars embedded in concrete, particularly when concrete with high compressive strength (larger than $50 \mathrm{MPa}$ ) or dowel rebars with high yield strength (larger than $400 \mathrm{MPa}$ ) are used.

\section{Test Program for Dowel Behavior of Rebars in Concrete}

In this study, an extensive experimental program was conducted to investigate the dowel behavior of the rebars in a small concrete member. The test variables considered in the program were concrete compressive strength, rebar yield strength, rebar diameter, concrete specimen thickness, and rebar spacing. This section provides an overview of the program.

\subsection{Summary of Test Specimens}

3.1.1. Test Variables. Concrete compressive strength, rebar yield strength, and rebar diameter were considered as the primary test variables because they have been typically considered in literature $[5,11,12]$. Two target compressive strengths for concrete were considered, that is, 30 and $60 \mathrm{MPa}$, because a concrete compressive strength of $30 \mathrm{MPa}$ has been adopted for slabs in sliding slab tracks where a concrete anchor block with dowel bars would be

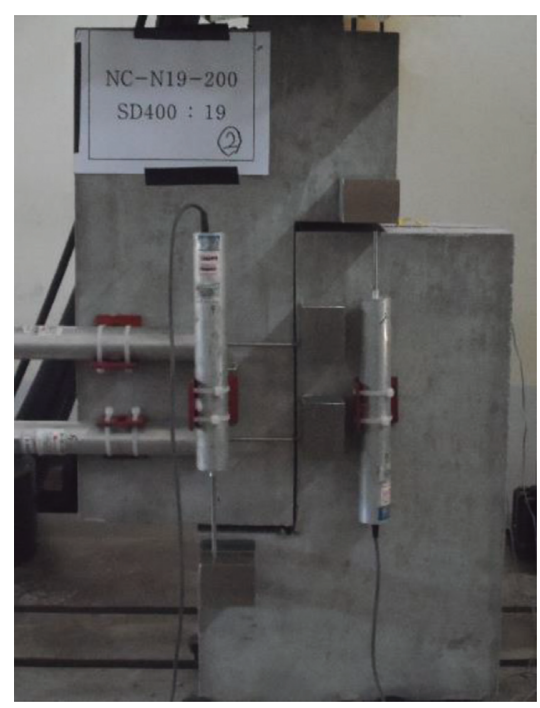

(a)

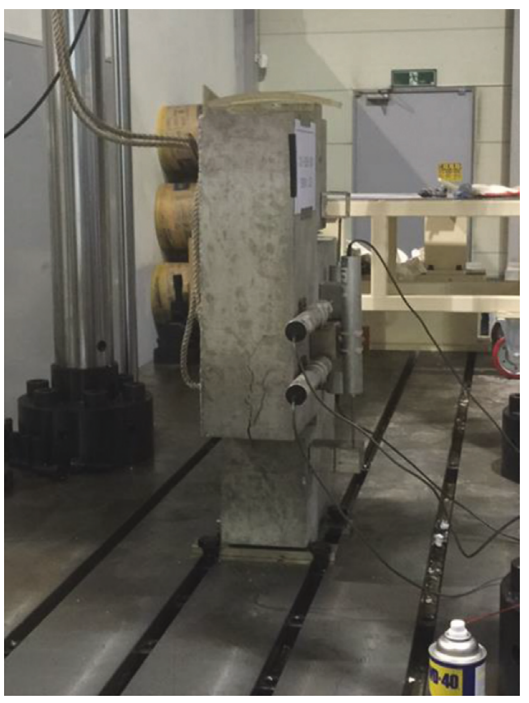

(b)

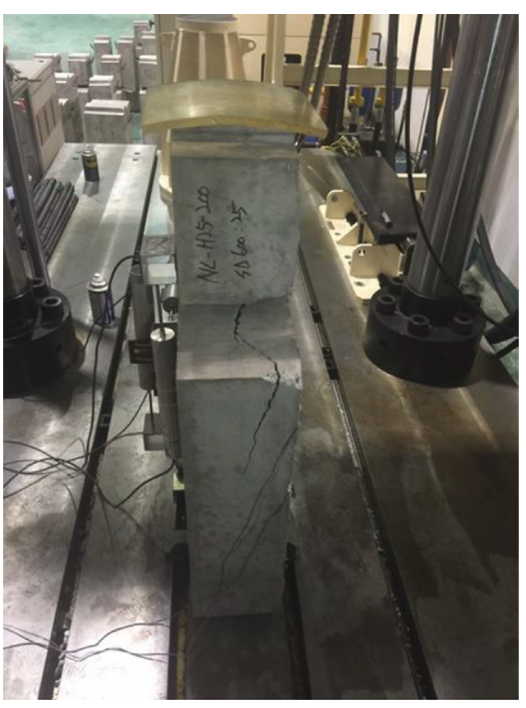

(c)

FIgURE 7: Typical failure mode of the test specimens. (a) Front view. (b) Left side. (c) Right side. 


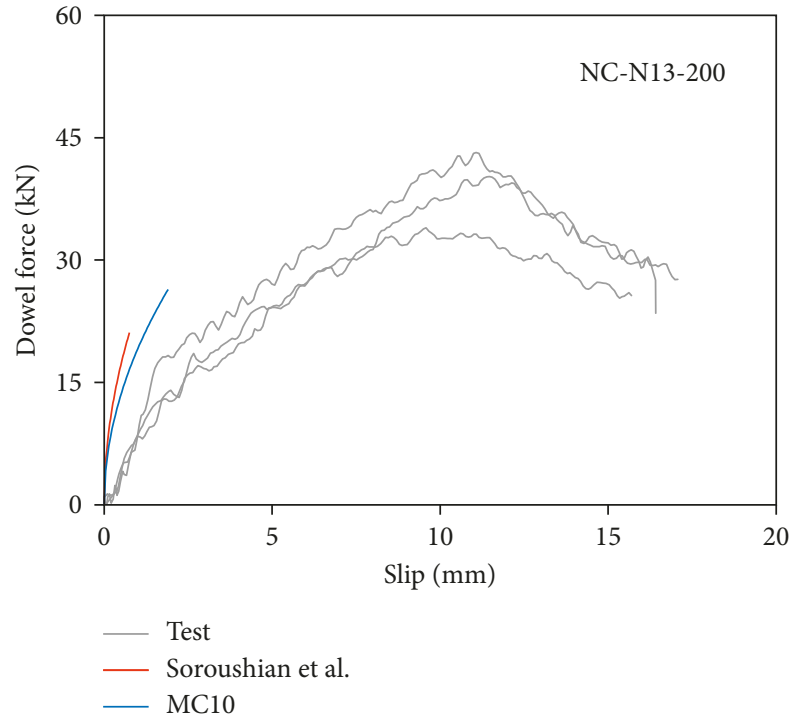

(a)

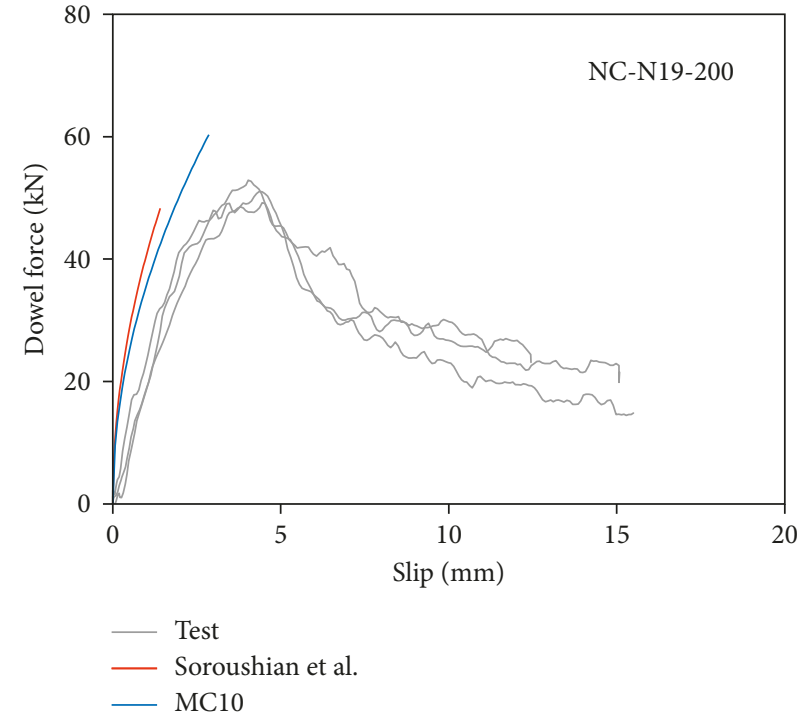

(b)

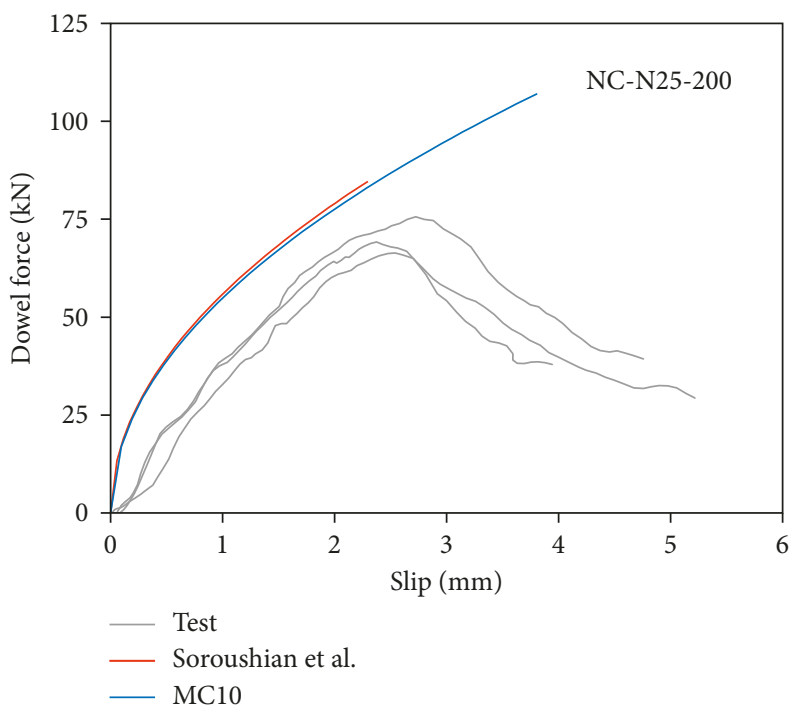

(c)

Figure 8: Shear slip-dowel force response, NC-200 series. (a) NC-N13-200. (b) NC-N19-200. (c) NC-N25-200.

embedded. In addition, $60 \mathrm{MPa}$ was considered because high strength concrete would be adopted in future. Yield strengths of $400 \mathrm{MPa}$ and $600 \mathrm{MPa}$ were considered for the dowel rebar. Three kinds of nominal rebar diameters were considered, that is, $12.7,19.1$, and $25.4 \mathrm{~mm}$. In addition to the primary test variables, the effects of concrete specimen thickness and dowel rebar spacing were considered.

The test specimens were designed based on the specimens used in previous studies [5]. In the test specimens, several cases were considered for the spacing of the dowel bars, according to the rebar arrangement in the concrete decks of railway bridges. Hence, considering that the longitudinal and lateral rebar spacings in the concrete deck are generally $150 \mathrm{~mm}$, the thickness of the specimen and the spacing of the dowel rebar in the specimens were set as 150 , 200 , or $250 \mathrm{~mm}$.

The details of the test variables are provided in Table 2 and Figure 3.

3.1.2. Details of Test Specimens. Considering the test variables, the shape of the specimen including the dowel rebar arrangement is presented in Figure 4. As shown in the figure, to eliminate the contribution of concrete friction along the concrete interface, a smooth thin plate with a thickness of $0.2 \mathrm{~mm}$ is installed in the specimens, along the direction of applied load. Two dowel rebars are arranged through the thin plate so that only the rebars can contribute against the applied load. 
TABle 4: Comparison on the maximum dowel force.

\begin{tabular}{|c|c|c|c|c|c|}
\hline Specimen & Test & Soroushian et al. & Randle (detailed) & Randle (simple) & MC10 \\
\hline NC-N13-200 & 39.3 & 21.1 & 26.4 & 25.8 & 27.7 \\
\hline NC-N19-150 & 47.4 & 48.3 & 60.3 & 58.2 & 63.2 \\
\hline NC-N19-200 & 51.2 & 48.3 & 60.3 & 58.2 & 63.2 \\
\hline NC-N19-250 & 56.0 & 48.3 & 60.3 & 58.2 & 63.2 \\
\hline NC-N25-200 & 70.6 & 84.7 & 107.1 & 101.4 & 112.2 \\
\hline NC-H13-200 & 46.4 & 26.5 & 31.3 & 29.3 & 32.8 \\
\hline NC-H19-200 & 55.6 & 57.3 & 67.4 & 64.0 & 70.7 \\
\hline NC-H25-200 & 73.5 & 100.9 & 119.2 & 111.6 & 125.0 \\
\hline HC-N13-200 & 65.8 & 24.6 & 38.0 & 44.2 & 40.2 \\
\hline HC-N19-200 & 66.1 & 53.9 & 87.6 & 95.9 & 91.8 \\
\hline HC-N25-200 & 99.8 & 92.4 & 155.4 & 164.1 & 162.9 \\
\hline HC-H13-200 & 60.8 & 30.0 & 45.4 & 47.9 & 46.2 \\
\hline HC-H19-150 & 81.6 & 62.9 & 97.9 & 102.1 & 102.6 \\
\hline HC-H19-200 & 85.2 & 62.9 & 97.9 & 102.1 & 102.6 \\
\hline HC-H19-250 & 77.5 & 62.9 & 97.9 & 102.1 & 102.6 \\
\hline HC-H25-200 & 99.1 & 108.7 & 173.1 & 175.1 & 181.5 \\
\hline NC-N19-200-2 & 54.5 & 48.3 & 60.3 & 58.2 & 63.2 \\
\hline NC-N19-200-2.5 & 62.7 & 48.3 & 60.3 & 58.2 & 63.2 \\
\hline
\end{tabular}

Unit: kN.

The spacing of the two dowel bars was set as 150,200 , or $250 \mathrm{~mm}$ to simulate the spacing of the dowel rebars along the direction of applied shear force. To consider the effect of the effective concrete width surrounding the dowel rebars in the lateral direction, the thickness of the specimens was set as $150 \mathrm{~mm}$ in most cases as rebar spacing is generally $150 \mathrm{~mm}$ in bridge decks. In addition, two more thicknesses of 200 and $250 \mathrm{~mm}$ were considered.

Relatively large amounts of D19 reinforcing bars were embedded close to the loading area to prevent undesirable local failure due to unintentional concrete collapse.

3.1.3. Instrumentation. Figure 5 shows the details of the instrumentation used to measure the dowel behavior of rebars during the test. As shown in the figure, four LVDTs are attached to the specimen surface; two LVDTs are attached along the direction of the applied load to measure shear slip along the interface between concrete blocks, and two more LVDTs are attached along the dowel rebars to measure interface opening during the test. As two LVDTs are used as one set, the average shear slip and interface opening can be evaluated from measured data. In addition to the LVDTs, two electric strain gauges are attached on the dowel rebar before concrete casting. When the specimen is fabricated, the electric gauges are placed at the interface such that the strain of the dowel rebars can be measured during the test.

3.2. Material Properties. To measure the actual compressive strength of concrete, $\phi 100 \times 200$ cylinders were fabricated when concrete was casted into the specimens. The actual concrete compressive strength was measured during the test for the dowel behavior of rebars. It is noted that the tests for concrete compressive strength and dowel behavior were conducted at least 28 days after concrete casting. In the compression test with the cylinders, the average compressive strength of concrete for the $\mathrm{NC}$ and $\mathrm{HC}$ series was measured as $32.1 \mathrm{MPa}$ and $67.6 \mathrm{MPa}$, respectively.

To measure the yield strength of the dowel rebars, direct tension tests were conducted with the rebars used as dowel rebars in the specimens. The tests were conducted according to the procedure presented in ISO 6892-1: 2009 [14]. The yield strengths of the rebars were evaluated through the $0.2 \%$ offset method using the stress-strain response of the rebars, and they are summarized in Table 3. As shown in the table, the dowel rebars used in the test specimens exhibit yield strengths exceeding the nominal yield strength of $400 \mathrm{MPa}$ or $600 \mathrm{MPa}$.

3.3. Test Procedure. To investigate the dowel behavior of rebars, load was applied in the direction along the interface on the bearing plates placed on the test specimens. A $1000 \mathrm{kN}$ machine was used to apply the load. Practically, it is hard to attain shear friction along the interface because of the repeated loading due to trains. Therefore, prior to conducting the test, the load corresponding to $5-20 \%$ of the design capacity for the maximum dowel force was repeatedly applied 25 times to remove the shear friction due to adhesion between the thin plate and concrete matrix. The cyclic preloading process was referred to the standard test procedure of stud shear connectors provided in Eurocode 4, B.2 [15]. Then, a static loading test was conducted at a displacement control rate of $1 \mathrm{~mm}$ per minute. Figure 6 shows the test setup before the load is applied. 


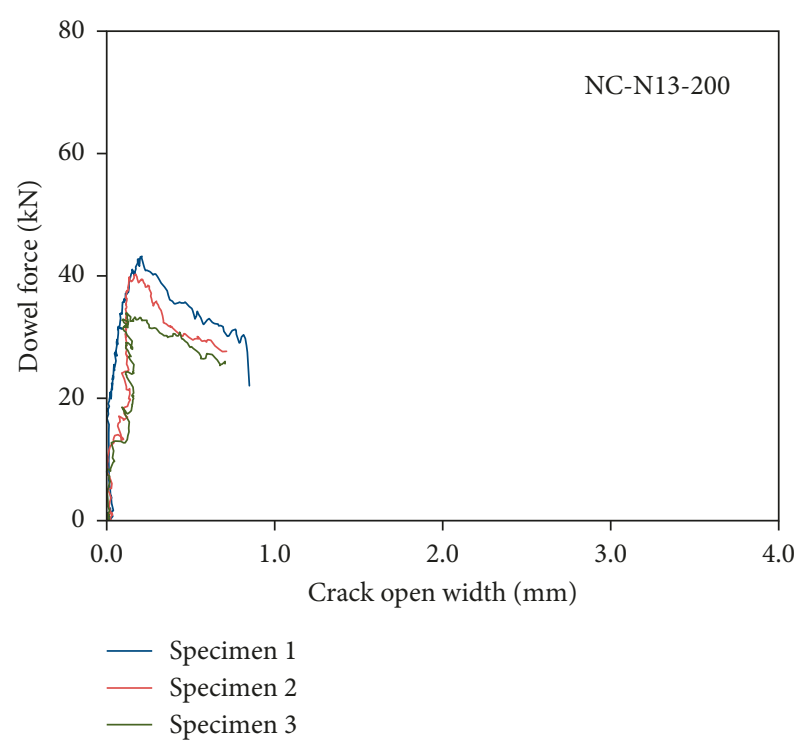

(a)

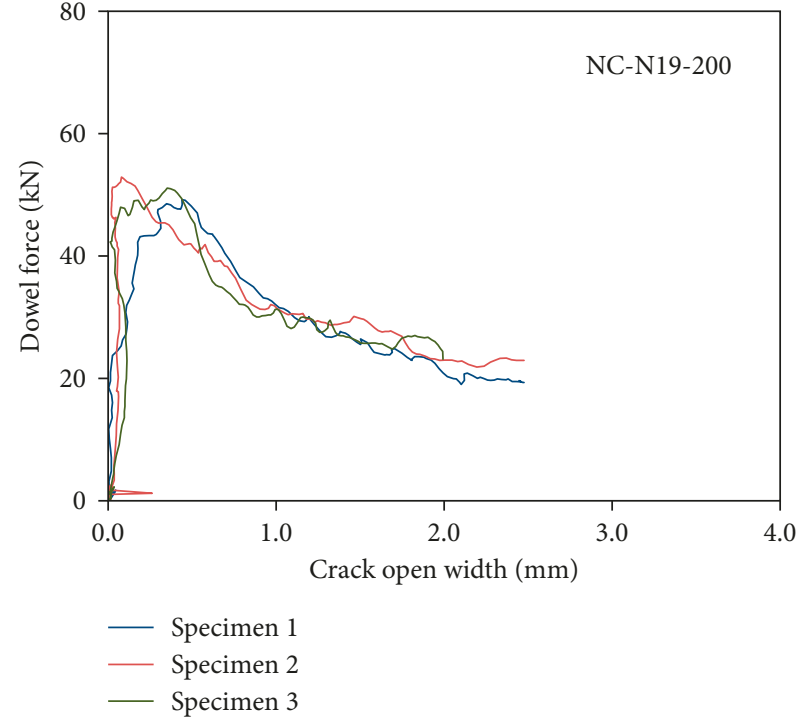

(b)

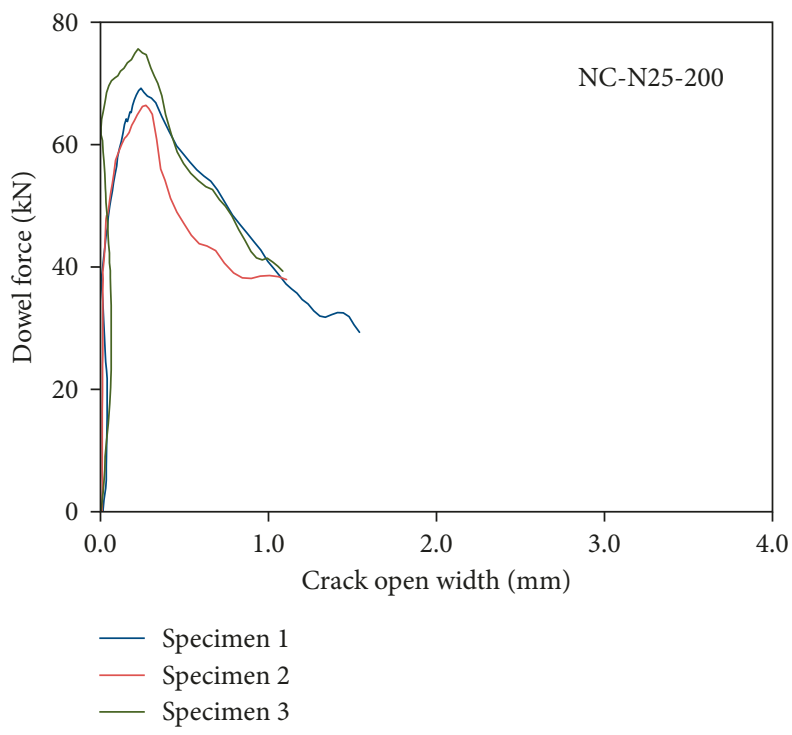

(c)

Figure 9: Interface opening-dowel force response, NC-200 series. (a) NC-N13-200. (b) NC-N19-200. (c) NC-N25-200.

\section{Test Results and Investigation}

\subsection{Failure Mode and Dowel Behavior of Rebars}

4.1.1. Failure Mode. Crack patterns were observed during the test to investigate the typical failure mode for the dowel behavior of rebars. No specimen exhibited splitting cracks before experiencing the maximum dowel force. After the maximum dowel force was reached, the applied force decreased considerably as concrete splitting cracks occurred under the dowel rebars. The typical crack patterns observed after the test are shown in Figure 7.

It can be inferred from these patterns that the shear resistance capacity due to the dowel behavior of the rebars is significantly influenced by the compressive strength of the concrete that supports the rebars, rather than by the yield strength of the rebars. According to the failure mode observed through the test, the maximum dowel force of the rebars can be increased by controlling concrete splitting cracks through the confinement effect, which can be attained by enclosing the concrete close to the dowel rebars with reinforcing bars.

4.1.2. Shear Slip-Dowel Force Responses. The representative shear slip-dowel force responses are presented in Figure 8. These responses were obtained from the tests for specimens NC-N13-200, NC-N19-200, and NC-N25-200. For detailed 


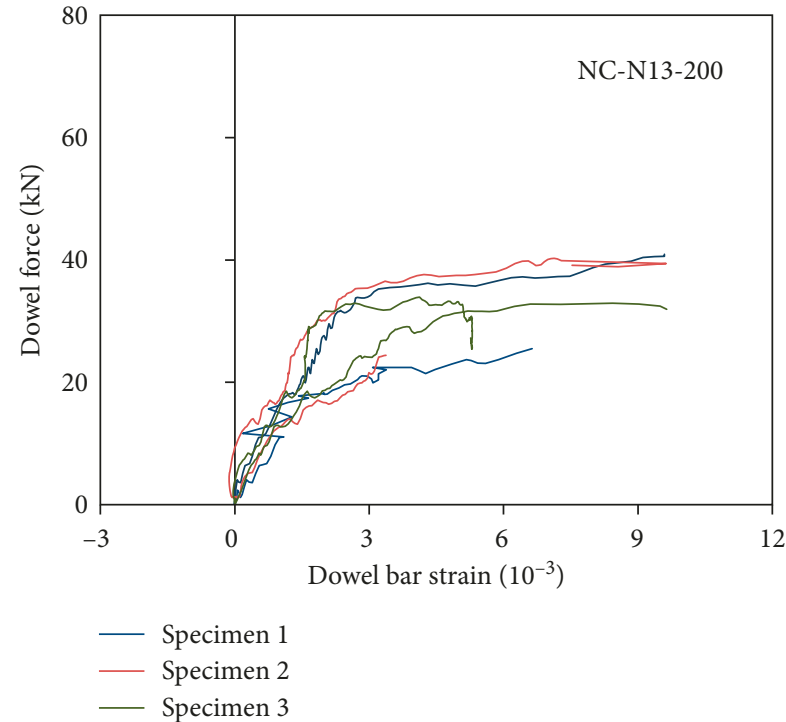

(a)

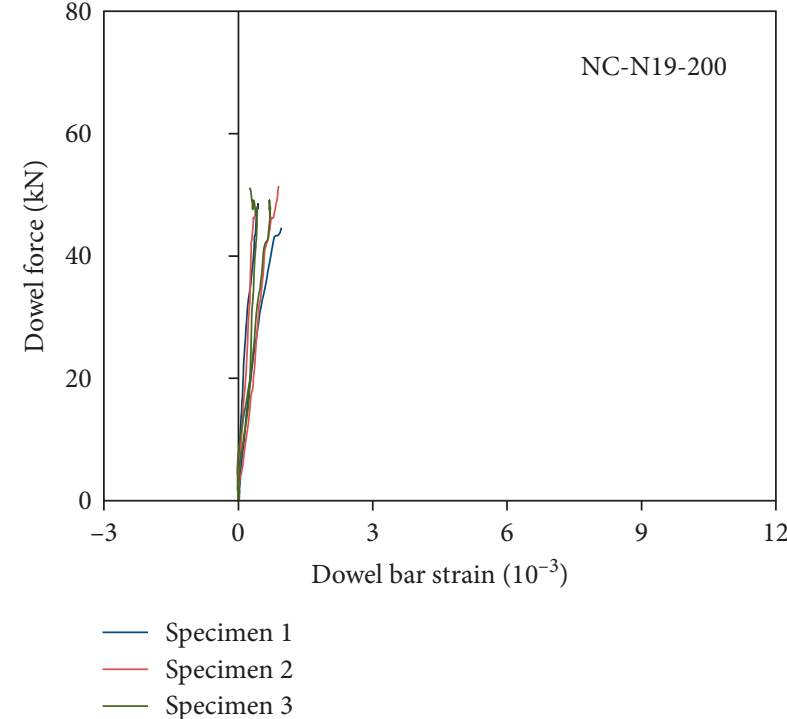

(b)

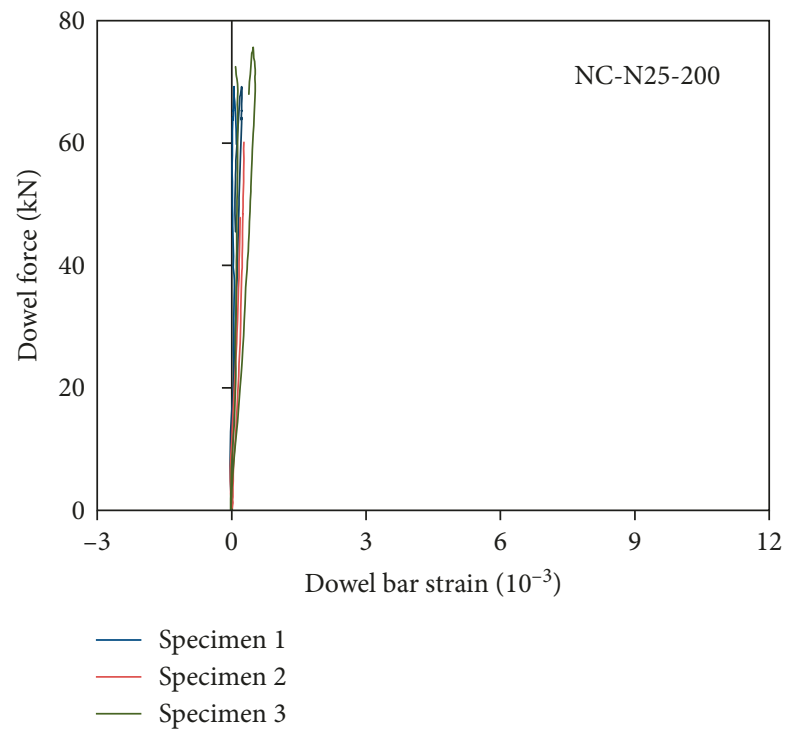

(c)

Figure 10: Dowel rebar strain-dowel force response, NC-200 series. (a) NC-N13-200. (b) NC-N19-200. (c) NC-N25-200.

analysis, the test results were compared with the dowel behaviors predicted by Soroushian et al. [5] and MC10 [12], who evaluated the maximum dowel force in addition to the shear slip-dowel force response. It is noted that MC10 predicted the shear slip corresponding to the maximum dowel force between 0.1 and 0.2 times the dowel rebar diameter. Hence, in this study, 0.15 times the dowel rebar diameter was selected to predict the shear slip-dowel force response.

As shown in Figure 8(a), in specimen NC-N13-200, the maximum dowel force measured through the test is $39.3 \mathrm{kN}$, which is significantly higher than the maximum dowel forces of $21.1 \mathrm{kN}$ and $26.4 \mathrm{kN}$ predicted by Soroushian et al. [5] and MC10 [12], respectively. This was primarily due to the small diameter of the dowel rebars.
Because of the small diameter, the kinking effect after the yielding of the dowel rebars contributed considerably to the dowel force before the test specimen exhibited splitting cracks under the dowel rebars. This phenomenon can also be inferred from the shear slip-dowel force response. The stiffness at a shear slip larger than 0.15 times the nominal diameter of the dowel rebars was significantly smaller than that at the earlier stage. In general, existing models $[5,12]$ do not consider the kinking effect of dowel rebars in the evaluation of the maximum dowel force. Therefore, when the dowel behavior at relatively low stiffness is excluded, the shear resistance capacity due to the dowel behavior of rebars measured through the test is only slightly different from the predictions of existing models. However, the predicted stiffness is higher than the test results when shear 


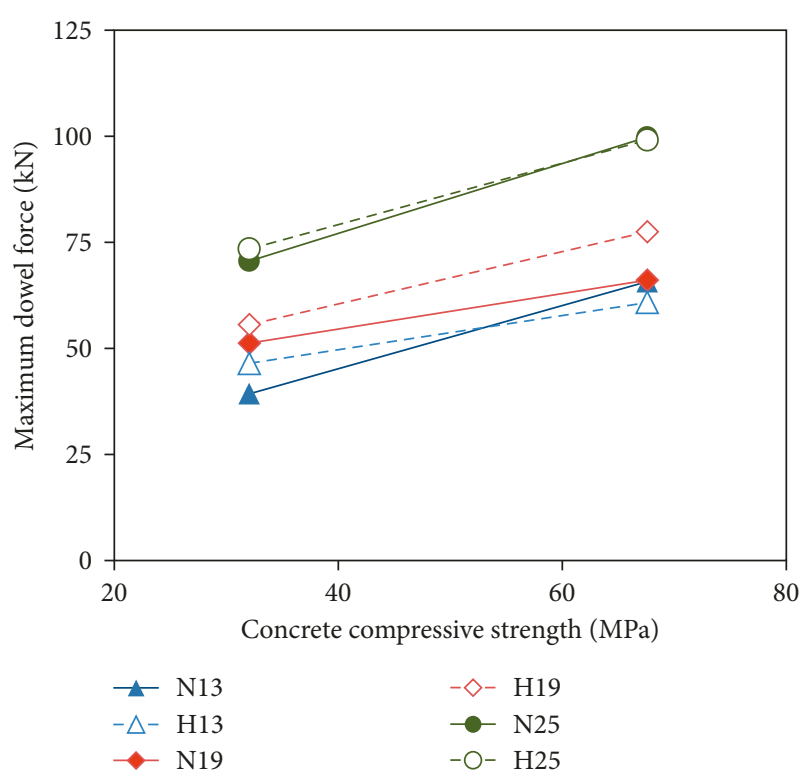

FIGURE 11: Effect of concrete compressive strength on the maximum dowel force.

slip is not larger than 0.15 times the nominal diameter of the dowel rebars.

Figure 8(b) shows the dowel force-shear slip responses for specimen NC-N19-200, which were measured using dowel rebars with a nominal yield strength of $400 \mathrm{MPa}$ in concrete with a nominal compressive strength of $30 \mathrm{MPa}$. As shown in the figure, the two-phase response before the maximum dowel force that is observed in the test results for N13 dowel rebars is not observed in the test results for N19 dowel rebars. This indicates that the specimen that used the N19 dowel rebars exhibited the maximum dowel force before the kinking effect became apparent. As the kinking effect is not observed in the test with N25 dowel rebars, as seen in Figure 8(c), only the dowel rebars with small diameters exhibit considerable kinking before splitting cracks are observed in the concrete specimen.

In addition, the shear slip corresponding to the maximum dowel force decreases as dowel rebar diameter increases (Figure 8). As summarized in Table 4, this result is considerably different from the results of existing models such as MC10 [12] and Soroushian et al. [5], which predict increase in the shear slip at the maximum dowel force with dowel rebar diameter. The overall stiffness of the dowel rebar before reaching the maximum dowel force is overestimated by existing models. Therefore, further theoretical investigation is required for the dowel behavior of the rebars in a small concrete member.

4.1.3. Interface Opening and Dowel Rebar Strain. Dowel force-interface opening responses are presented in Figure 9. Interface opening is calculated as the average of the values obtained through the LVDTs attached

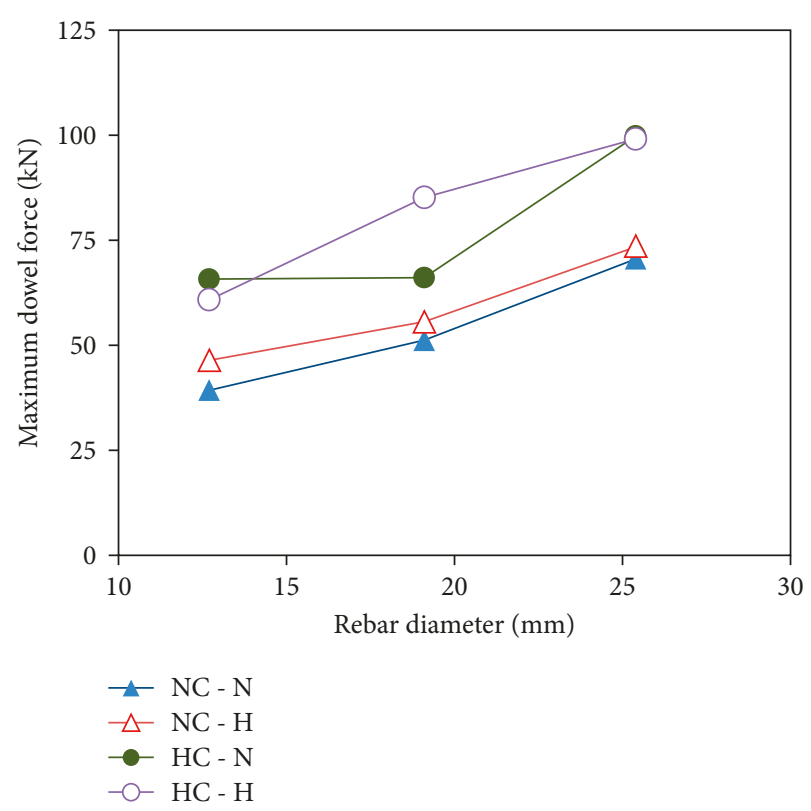

(a)

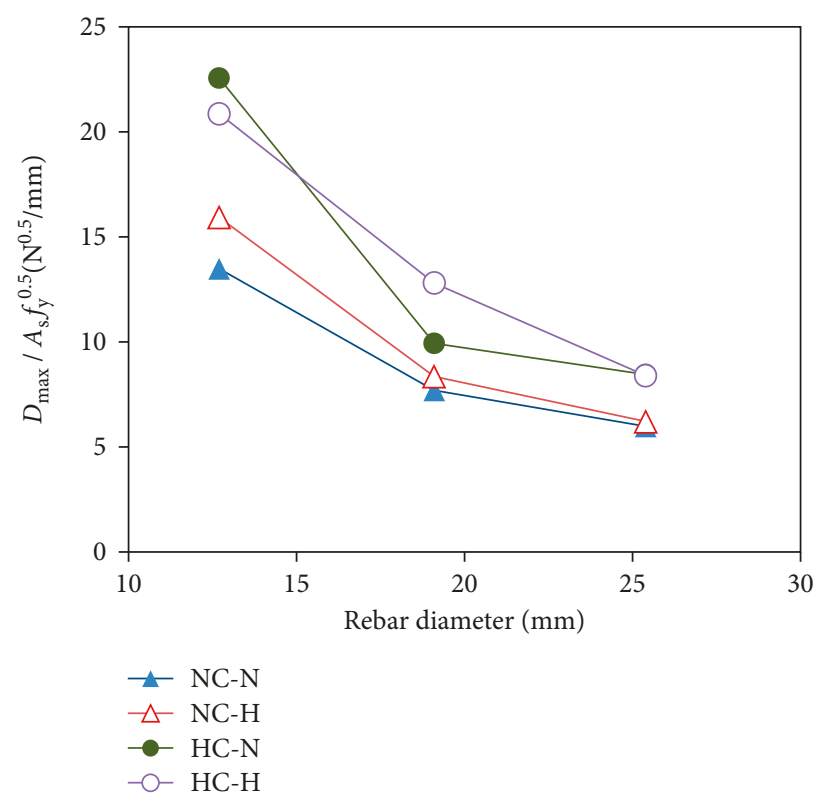

(b)

Figure 12: Effect of dowel rebar diameter on the maximum dowel force: (a) maximum dowel force; (b) normalized maximum dowel force.

perpendicular to the interface between the concrete blocks. As shown in the figure, the interface opening for all specimens is extremely small until the maximum dowel force is reached, after which interface opening increases rapidly. MC90 reported that the maximum dowel force can be reduced by a large interface opening [16]; thus, it is important to keep the interface opening small during the test to measure the actual maximum dowel force. Consequently, the test results obtained in this study are reliable for measuring the maximum dowel force under a small interface opening. 
Figure 10 shows the dowel force-dowel rebar strain responses for the specimens with normal strength concrete (NC series) and dowel rebars ( $\mathrm{N}$ series). Three dowel rebar diameters are considered to investigate the effect of the diameter on the response. It is noted that the strains of the dowel rebars were measured through two electronic strain gauges attached on the rebars at the interface. As seen in the figures, the strains of the specimens with N19 or N25 dowel rebars do not increase considerably until the maximum dowel force is reached. On the contrary, the strains of the specimens with N13 dowel rebars increase significantly before the maximum dowel force is reached. In addition, the dowel force in these specimens increases considerably even after the yielding of the dowel rebars, primarily owing to the kinking effect.

\subsection{Effect of Test Variables on Dowel Behavior}

4.2.1. Effect of Concrete Compressive Strength and Dowel Rebar Strength. The effect of concrete compressive strength and dowel rebar strength on the maximum dowel force is shown in Figure 11. Each point in the figure represents the average of three test results under the same test variables. The maximum dowel force increases with concrete compressive strength; the average increase in the maximum dowel force is $40.5 \%$ for an average increase of $110.9 \%$ in concrete compressive strength. This result is in agreement with previous models $[5,11,12]$, which showed that the maximum dowel force is proportional to the square root of concrete compressive strength. In contrast, the effect of the yield strength of the dowel rebars is not as significant as that of concrete compressive strength; the average increase in the maximum dowel force is only $6.7 \%$ for an average increase of $29.7 \%$ in dowel rebar yield strength. This result indicates that existing models $[11,12]$ tend to overestimate the contribution of dowel rebar yield strength to the maximum dowel force. It can be seen from the figure that concrete compressive strength has a stronger effect on the maximum dowel force, as compared to the yield strength of dowel rebars. In other words, the bearing strength of the concrete under dowel rebars strongly affects the maximum dowel force.

4.2.2. Effect of Dowel Rebar Diameter. Figure 12 shows the effect of dowel rebar diameter on the maximum dowel force. As shown in Figure 12(a), the maximum dowel force increases with dowel rebar diameter. This trend is in agreement with existing models $[5,11,12]$; however, there is considerable difference in how strong the effect of the increase in dowel rebar diameter is on the maximum dowel force. For a more detailed investigation, the maximum dowel force is normalized using the nominal area and the square root of the yield strength of the dowel rebar, as shown in Figure 12(b). Existing models generally overestimate the contribution of dowel rebar diameter to the maximum dowel force. As the strain of the dowel rebar at the maximum dowel force is significantly affected by dowel

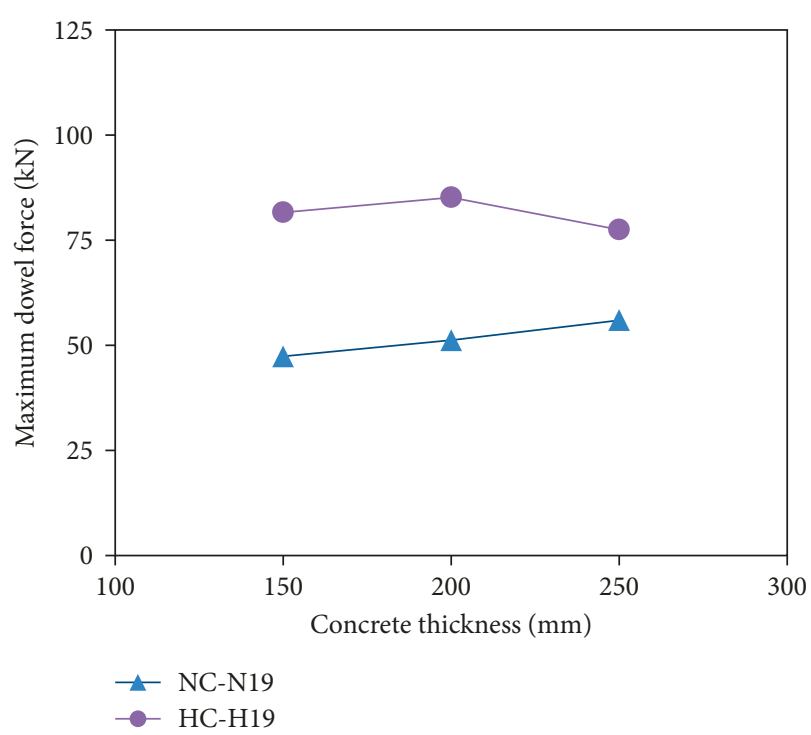

FIGURE 13: Effect of concrete specimen thickness on the maximum dowel force.

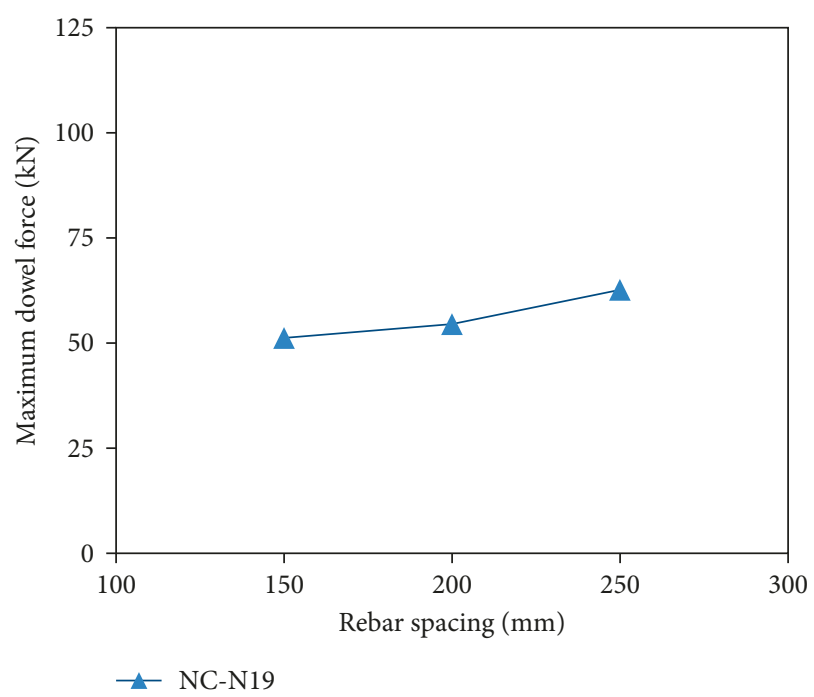

FIGURE 14: Effect of dowel rebar spacing on the maximum dowel force.

rebar diameter, as observed through the comparison of the results shown in Figure 8, a more rational prediction model is required.

\subsubsection{Effect of Concrete Specimen Thickness and Dowel Rebar} Spacing. The effect of concrete specimen thickness and dowel rebar spacing is investigated using Figures 13 and 14 . As shown in Figure 13, the maximum dowel force is not considerably affected by a concrete specimen thickness of more than $150 \mathrm{~mm}$. As shown in Figure 14, the maximum dowel force increases by 6.4 and $22.4 \%$ as dowel rebar spacing increases by 33.3 and $66.7 \%$, respectively. Therefore, 


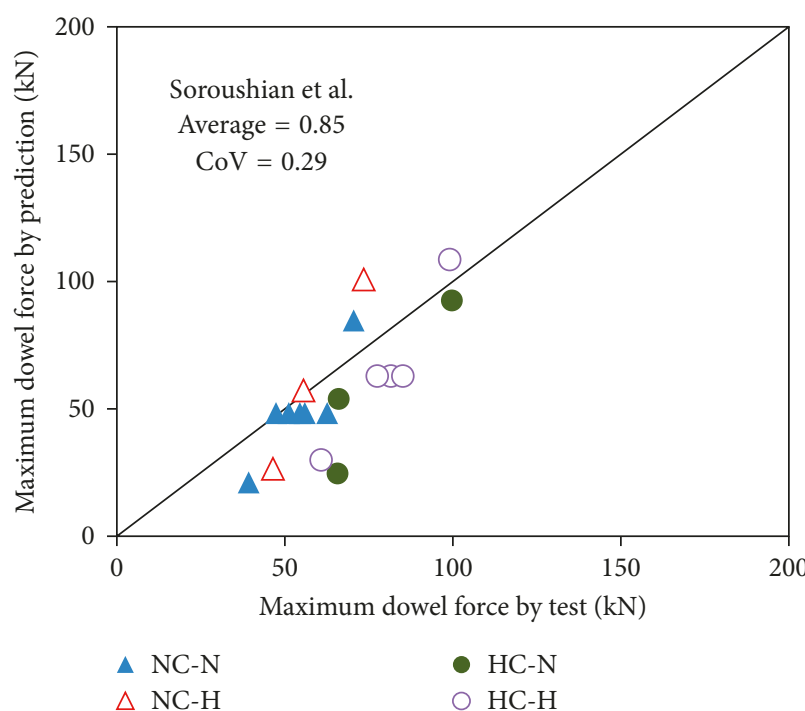

(a)

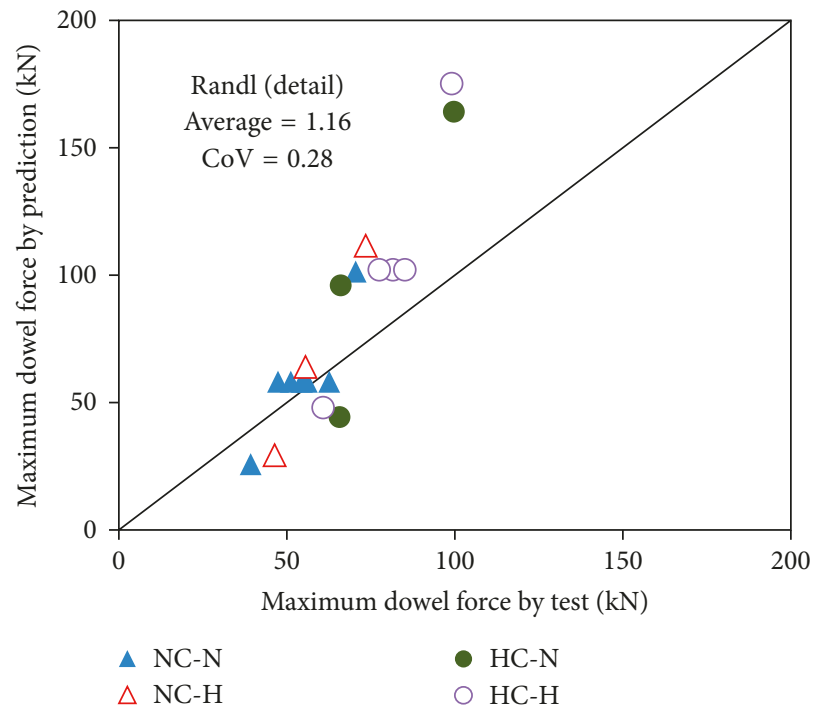

(c)

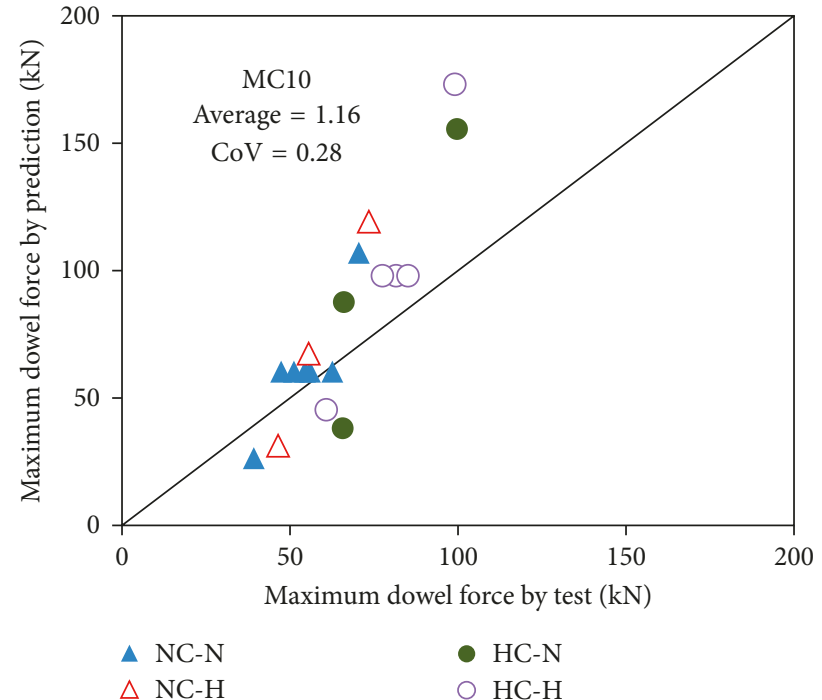

(b)

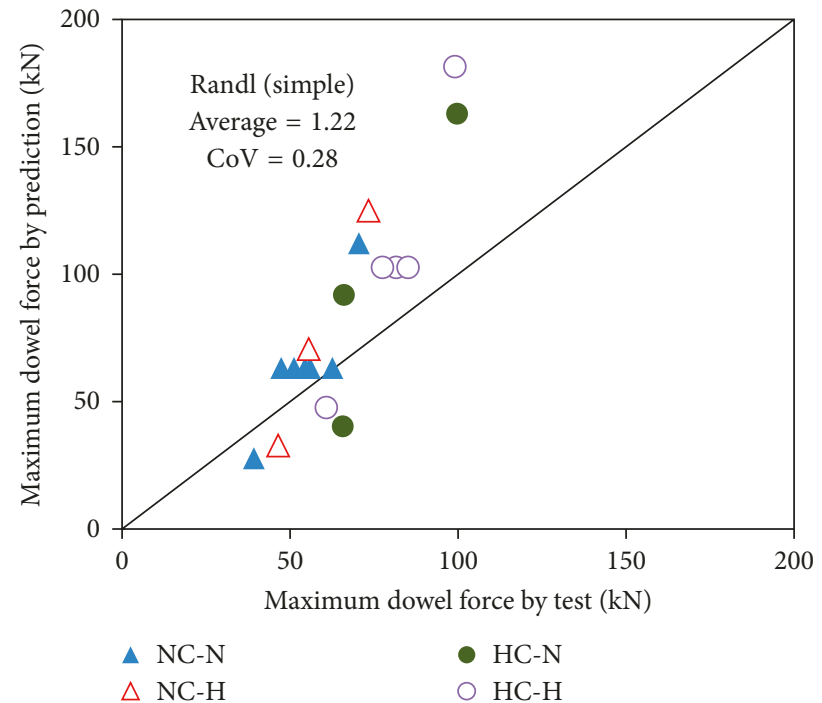

(d)

Figure 15: Comparison of the test results and several models on the maximum dowel force. (a) Soroushian et al. (b) MC10. (c) Randl (detail). (d) Randl (simple).

the maximum dowel force is not strongly affected by a dowel rebar spacing of more than $150 \mathrm{~mm}$. Consequently, it can be concluded that the maximum dowel force is only weakly affected by concrete specimen thickness and dowel rebar spacing in the ranges considered in this study.

\section{Comparison with Design Specification and Previous Models}

The maximum dowel force measured through the tests is provided in Table 4. Each value is the average of three test results for a given test variable. In addition, the maximum dowel forces predicted by several existing models $[5,11,12]$ are presented in the table. In existing models, the actual concrete compressive strength and dowel rebar yield strength are considered in the calculation of the maximum dowel force. Figure 15 shows the maximum dowel forces for a more detailed comparison between the test results and predictions, and the ratios of the test results to the predictions are presented in Table 5 and Figure 16, as provided in JCSS [17] and Holický et al. [18].

The test results exhibit slightly better agreement with the prediction results of MC10 [12] and Randl [11] than with the results of Soroushian et al. [5]. In the prediction results of Soroushian et al., the maximum dowel force is generally overestimated for the specimens with large dowel rebar diameters (see specimens NC-N25-200, NC-H25-200, and $\mathrm{HC}-\mathrm{H} 25-200)$. This indicates that the contribution of the nominal area of dowel rebars is overestimated. 
TABle 5: Test/prediction ratio on the maximum dowel force.

\begin{tabular}{|c|c|c|c|c|}
\hline Specimen & Soroushian et al. & Randl (detailed) & Randl (simple) & MC10 \\
\hline NC-N13-200 & 1.86 & 1.52 & 1.42 & 1.49 \\
\hline NC-N19-150 & 0.98 & 0.81 & 0.75 & 0.79 \\
\hline NC-N19-200 & 1.06 & 0.88 & 0.81 & 0.85 \\
\hline NC-N19-250 & 1.16 & 0.96 & 0.89 & 0.93 \\
\hline NC-N25-200 & 0.83 & 0.70 & 0.63 & 0.66 \\
\hline NC-H13-200 & 1.75 & 1.58 & 1.42 & 1.49 \\
\hline NC-H19-200 & 0.97 & 0.87 & 0.79 & 0.82 \\
\hline NC-H25-200 & 0.73 & 0.66 & 0.59 & 0.62 \\
\hline HC-N13-200 & 2.68 & 1.49 & 1.64 & 1.73 \\
\hline HC-N19-200 & 1.23 & 0.69 & 0.72 & 0.75 \\
\hline HC-N25-200 & 1.08 & 0.61 & 0.61 & 0.64 \\
\hline HC-H13-200 & 2.03 & 1.27 & 1.28 & 1.34 \\
\hline HC-H19-150 & 1.30 & 0.80 & 0.80 & 0.83 \\
\hline HC-H19-200 & 1.35 & 0.83 & 0.83 & 0.87 \\
\hline HC-H19-250 & 1.23 & 0.76 & 0.76 & 0.79 \\
\hline HC-H25-200 & 0.91 & 0.57 & 0.55 & 0.57 \\
\hline NC-N19-200-2 & 1.13 & 0.94 & 0.86 & 0.90 \\
\hline NC-N19-200-2.5 & 1.30 & 1.08 & 0.99 & 1.04 \\
\hline Average & 1.31 & 0.95 & 0.91 & 0.95 \\
\hline $\mathrm{CoV}$ & 0.36 & 0.33 & 0.34 & 0.34 \\
\hline
\end{tabular}

On the contrary, the maximum dowel force is considerably underestimated for the specimens with small dowel rebar diameters (see specimens NC-N13-200, NC-H13-200, HC-N13-200, and HC-H13-200). This is primarily because Soroushian et al. [5] considered only the bearing failure of the concrete under dowel rebars [13] and did not include the kinking effect observed in the specimens with small dowel rebar diameters.

Unlike Soroushian et al., the maximum dowel force is overestimated in several cases in the prediction results of MC10 [12] and Randl [11]. This tendency is more evident for the specimens with large rebar diameters, such as NC-N25-200, NC-H25-200, HC-N25-200, and HC-H25200. For these specimens, the ratio of the predictions to the test results of the maximum dowel force is larger than 1.50. The maximum dowel force is considerably underestimated only for the specimens with small rebar diameters, such as NC-N13-200, NC-H13-200, HC-N13-200, and HC-H13-200, because the kinking effect is not considered.

Consequently, for all test variables, the test results of the maximum dowel force for normal strength concrete and a dowel rebar diameter of $19 \mathrm{~mm}$ are in good agreement with all existing models considered in this study. The predictions of the existing models become more scattered as either dowel rebar diameter or the material strength of concrete or dowel rebars is changed. Therefore, further study is required to develop a more rational model to accurately represent the actual dowel behavior in a small concrete member.

\section{Conclusions}

In this study, an extensive experimental program was conducted to investigate the dowel behavior of the rebars embedded in a small concrete member. In the experimental program, 54 specimens were fabricated and tested. Test variables were concrete compressive strength, dowel rebar yield strength and diameter, concrete specimen thickness, and dowel rebar spacing. The test results were compared with the predictions of three existing models to investigate the applicability of the models. The results obtained in this study can be summarized as follows:

(i) Even though the three existing models considered concrete compressive strength, dowel rebar yield strength, and dowel rebar diameter simultaneously, the predicted maximum dowel forces were considerably different, particularly when a high strength material was used.

(ii) In all specimens, splitting cracks at failure occurred in the concrete under the dowel rebars regardless of the test variables. It can be inferred from the failure mode observed through the tests that splitting cracks have a strong effect on the dowel behavior of the rebars embedded in a small concrete member.

(iii) In the specimens with dowel rebars of small diameters (N13 and H13 series), the kinking effect was strong and the yielding of the dowel rebars occurred before the maximum dowel force was reached. In contrast, the specimens with dowel rebars of large diameters exhibited neither the yielding of the dowel rebars nor a strong kinking effect.

(iv) The test results showed that the maximum dowel force increased with concrete compressive strength and dowel rebar diameter, while the effect of the yield strength of dowel rebars was not evident.

(v) There were no considerable effects of specimen thickness and dowel rebar spacing on the maximum dowel force. 


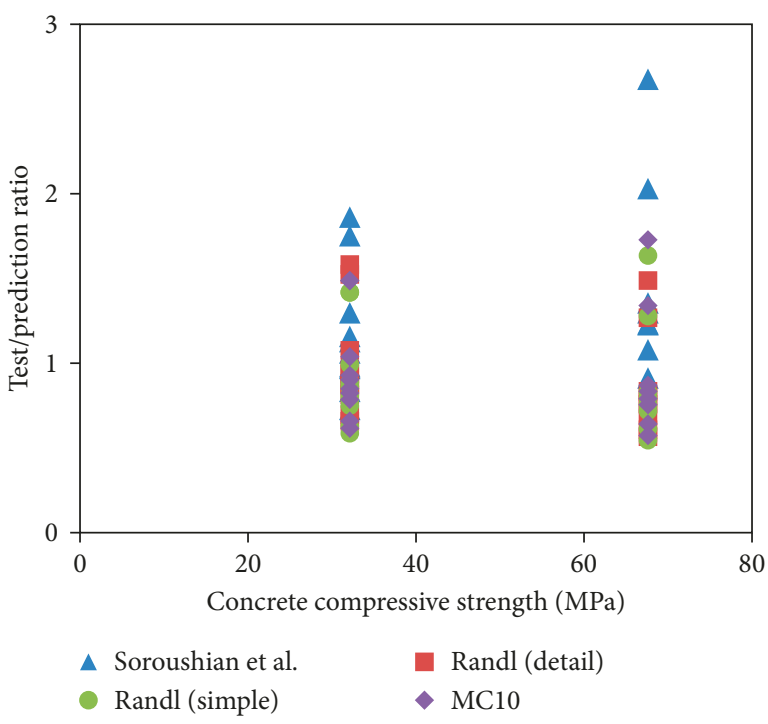

(a)

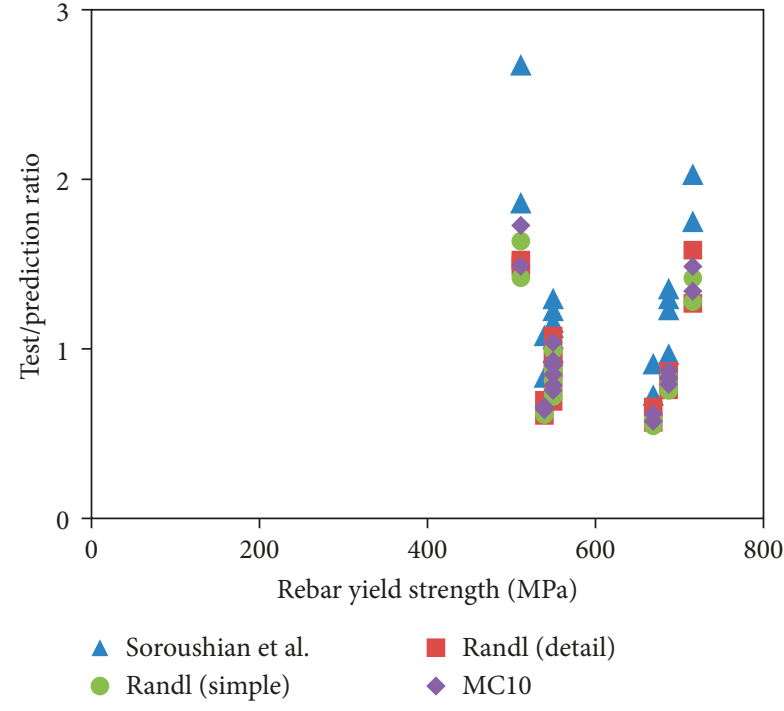

(b)

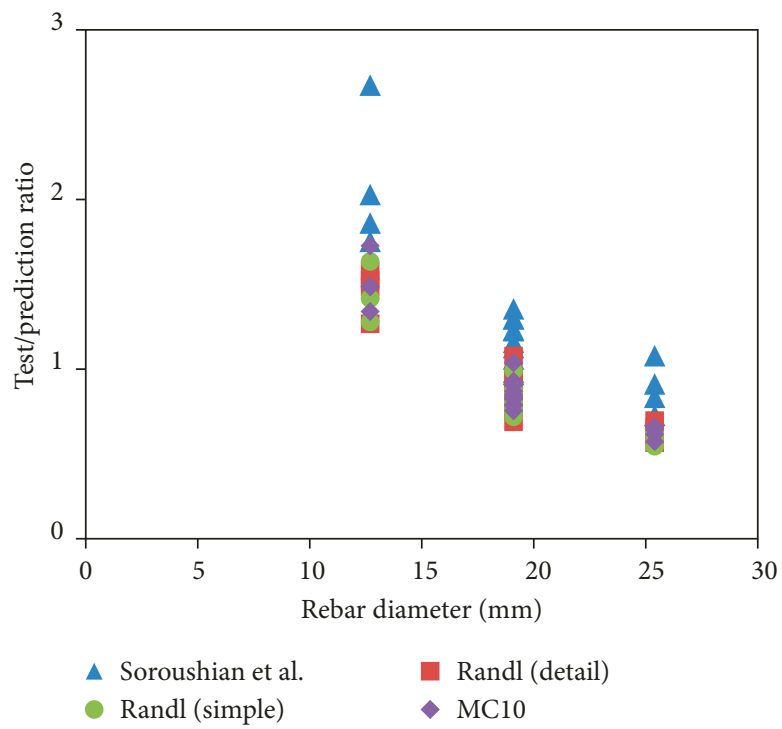

(c)

FIGURE 16: Effect of the test variables on the comparison for the maximum dowel force.

(vi) Unlike MC10 and Soroushian et al., who predicted that the shear slip corresponding to the maximum dowel force increases with dowel rebar diameter, the test results showed that shear slip at the maximum dowel force decreased as dowel rebar diameter increased.

(vii) The predictions of the existing models were significantly different from the maximum dowel forces measured in the tests. The existing models considerably underestimated the maximum dowel forces of the rebars with small diameters (N13 and H13 series) because the kinking effect was not considered. On the contrary, MC10 and Randl considerably overestimated the maximum dowel force of the dowel rebars with large diameters (N25 and $\mathrm{H} 25$ series). (viii) The results presented in this paper will be useful for evaluating the actual shear capacity of the lateral supporting blocks in which dowel rebars are embedded. For a more reasonable design of lateral supporting blocks, a more rational model is required to represent the dowel behavior of the rebars embedded in a small concrete member.

\section{Notations}

$A_{\mathrm{s}}$ : Cross-sectional area of dowel rebar $\left(\mathrm{mm}^{2}\right)$

$c$ : $\quad$ Length of crushed concrete zone underneath dowel bar (mm)

$D(s)$ : Dowel force $(\mathrm{N})$ for a given slip $s(\mathrm{~mm})$

$d_{\mathrm{b}}$ : $\quad$ Diameter of dowel rebar $(\mathrm{mm})$

$D_{\max }$ : Maximum dowel force $(\mathrm{N})$ 
$E_{\mathrm{s}}$ : $\quad$ Dowel bar modulus of elasticity $(\mathrm{MPa})$

$f_{\mathrm{b}}$ : Concrete bearing strength $(\mathrm{MPa})$

$f_{\mathrm{c}}^{\prime}$ : Concrete compressive strength $(\mathrm{MPa})$

$f_{\mathrm{cwm}}$ : Cube strength of concrete $(\mathrm{MPa})$

$f_{\mathrm{y}}$ : Yield strength of dowel rebar $(\mathrm{MPa})$

I: $\quad$ Second moment of inertia of dowel bar $\left(\mathrm{mm}_{4}\right)$

$K_{\mathrm{f}}$ : Concrete foundation modulus $(\mathrm{MPa} / \mathrm{mm})$

L: $\quad$ Characteristic length of dowel bar ( $\mathrm{mm})$

$p_{\max }$ : Maximum possible concrete pressure under dowel bar (MPa)

$s_{\max }: \quad$ Slip at $D_{\max }(\mathrm{mm})$

$T: \quad$ Dowel bar axial force $(\mathrm{N})$

$T_{\mathrm{y}}$ : $\quad$ Dowel bar yield axial force $(\mathrm{N})$

$\kappa_{2 \text {,max }}$ : Interaction coefficient for flexural resistance at $s_{\max }$.

\section{Conflicts of Interest}

The authors declare that they have no conflicts of interest.

\section{Acknowledgments}

This research was supported by a grant (17RTRP-B07156605) from Railroad Technology Research Program funded by Ministry of Land, Infrastructure and Transport of the Korean Government.

\section{References}

[1] K.-C. Lee, S. Y. Jang, and J. Lee, "Development of sliding slab track to reduce track-bridge interaction," in Proceedings of the 2017 First International Conference on Rail Transportation, Chengdu, China, July 2017.

[2] K.-C. Lee, S. Y. Jang, D.-K. Jung, H.-K. Byun, H.-K. Park, and T.-S. Yang, "Rail-structure interaction analysis of sliding slab track on bridge," in Proceedings of the 2015 Joint Rail Conference, San Jose, CA, USA., March 2015.

[3] K.-C. Lee, S. Y. Jang, J. Lee, and H.-S. Choi, "Comparative analysis of track-bridge interaction of sliding slab track and rail expansion joint for long-span railway bridge," Journal of Computational Structural Engineering Institute of Korea, vol. 29, no. 2, pp. 169-177, 2016, in Korean.

[4] S.-C. Lee, S. Y. Jang, and K.-C. Lee, "Evaluation of shear load carrying capacity of lateral supporting concrete block for sliding slab track considering construction joint," Journal of Computational Structural Engineering Institute of Korea, vol. 30, no. 1, pp. 55-61, 2017, in Korean.

[5] P. Soroushian, K. Obaseki, M. C. Rojas, and J. Sim, "Analysis of dowel bars acting against concrete core," ACI Journal Proceedings, vol. 83, no. 4, pp. 642-649, 1986.

[6] P. Soroushian, K. Obaseki, M. Rojas, and H. S. Najm, "Behavior of bars in dowel action against concrete cover," ACI Structural Journal, vol. 84, no. 2, pp. 170-176, 1987.

[7] E. E. Kazakoff, Dowel Action in Reinforced Concrete Construction (Beam-Column Connections), Master thesis, p. 95, Department of Engineering, The University of British Columbia, Vancouver, Canada, 1971.

[8] S. Dei Poli, M. Di Prisco, and P. G. Gambarova, "Shear response, deformations, and subgrade stiffness of a dowel bar embedded in concrete," ACI Structural Journal, vol. 89, no. 6, pp. 665-675, 1992.

[9] T. Paulay, R. Park, and M. H. Phillips, "Horizontal construction joints in cast-in place reinforced concrete," $A C I$
Special Publication SP-42 Shear in Reinforced Concrete, vol. 42, pp. 599-616, 1974.

[10] E. W. Bennett and S. Banerjee, "Strength of beam-column connections with dowel reinforcement," Structural Engineer, vol. 51, no. 4, pp. 133-139, 1976.

[11] N. Randl, "Load bearing behaviour of cast-in shear dowels," Beton- und Stahlbetonbau, vol. 102, no. 1, pp. 31-37, 2007.

[12] Comité Euro-International du Béton, Fib Model Code for Concrete Structures 2010, Ernst \& Sohn, Berlin, 2013.

[13] P. Soroushian, K. Obaseki, and M. C. Rojas, "Bearing strength and stiffness of concrete under reinforcing bars," ACI Materials Journal, vol. 84, no. 3, pp. 179-184, 1987.

[14] ISO 6892-1:2016, Metallic Materials-Tensile Testing-Part 1: Method of Test at Room Temperature, International Organization for Standardization, Geneva, Switzerland, 2016.

[15] Comité Euro-International du Béton, CEB-FIP Model Code 1990. Design Code, Thomas Telford, London, 1993.

[16] European Standard EN 1994-1-1:2004, "Eurocode 4: design of composite steel and concrete structures- part 1-1: general rules and rules for buildings, annex B.2," Tests on Shear Connectors, pp. 110-113, 2009.

[17] JCSS, JCSS Probabilistic Model Code: Joint Committee on Structural Safety, JCSS, Japan, 2001.

[18] M. Holický, J. V. Retief, and M. Sýkora, "Assessment of model uncertainties for structural resistance," Probabilistic Engineering Mechanics, vol. 45, pp. 188-197, 2016. 


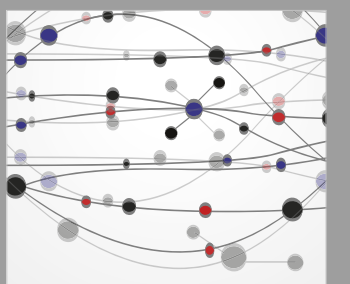

The Scientific World Journal
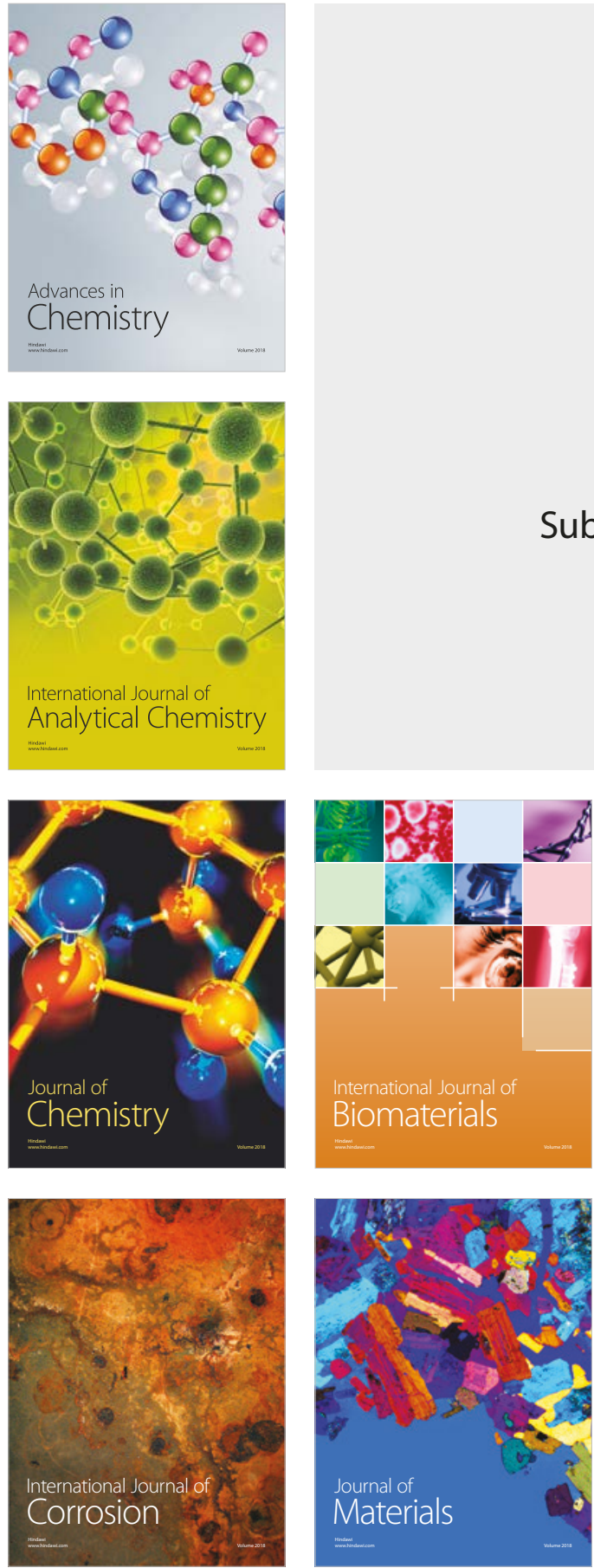

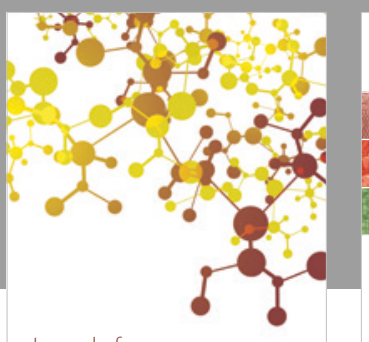

Journal of

Applied Chemistry
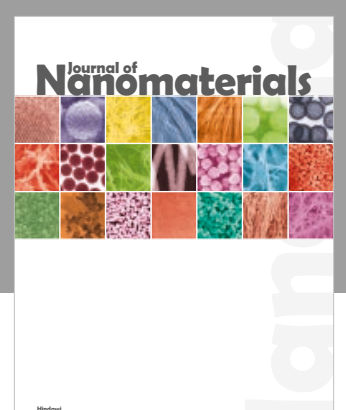

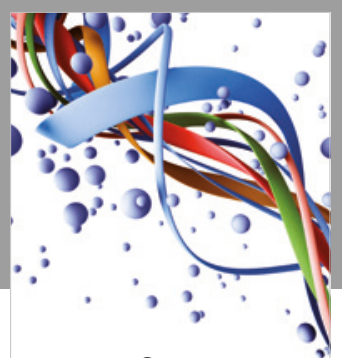

Scientifica

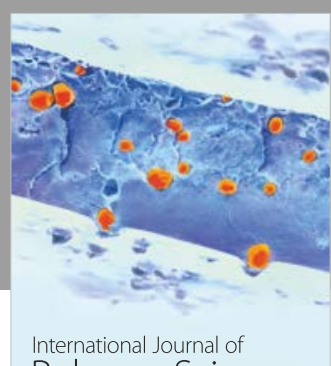

Polymer Science

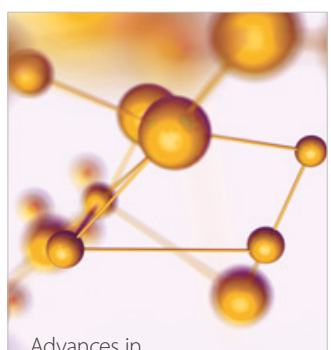

Physical Chemistry
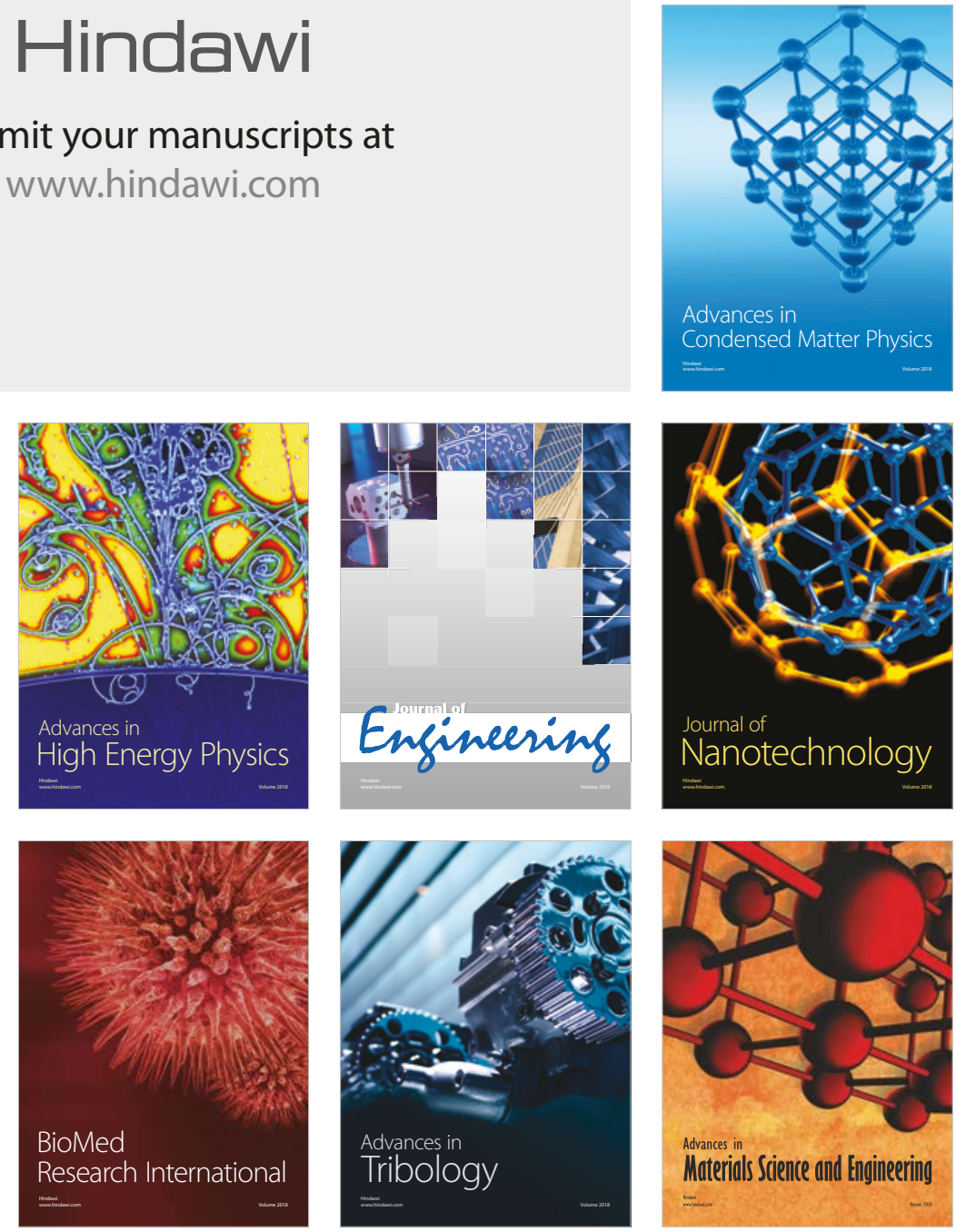